\title{
An investigation into teacher awareness of, and attitudes towards, English as a Lingua Franca within Business English instruction in the UK.
}

\section{i. Abstract}

This dissertation documents the research into Business English (BE) teacher awareness of, and attitudes towards, English as a Lingua Franca (ELF). Given that English has become the international language of global business and trade, used widely to communicate across linguistic and cultural borders, the argument is made that ELF is the most relevant paradigm for BE instruction, in contrast to the still currently dominant English as a Foreign Language (EFL) paradigm that has housed most English Language Teaching (ELT). A further argument is made that a number of what the author refers to as core 'ELF competences', primarily Intercultural Communicative Competence (ICC), accommodation strategies and aspects of the phonological Lingua Franca Core (LFC), are the most relevant and teachable aspects of 'ELF-talk' to BE learners.

The research took the form of a small Mixed Methods Research (MMR) case-study of a group of BE teachers based in the South of England, UK. Twelve participants completed questionnaires, modelled loosely on that used in Dewey's 2012 research into teacher awareness of ELF and ELT teacher training. A further two participants were selected for follow-up classroom observations and interviews.

A review of the literature indicates that teachers often possess limited awareness of the constructs of ELF or ICC and when there is awareness, demonstrate a conflict between their beliefs surrounding the relevance of these constructs to their teaching and their willingness or ability to apply those beliefs in practice. The findings from this research, however, do not support those claims and instead indicate relatively high levels of applied ELF awareness in practice. Due to the small-scale nature of this investigation it is impossible to infer that this difference in results emanates from the fact that the subjects in this research were $\mathrm{BE}$ as opposed to General English teachers, as has been the case in previous research, therefore implications for further research indicated by this study include a more widespread investigation into BE teacher awareness and attitudes towards ELF. 


\section{ii. Acknowledgments}

I would like to take this opportunity to acknowledge all the support I have received while working on this project. Firstly, thanks go to my supervisor, Jules Winchester who has helped guide my thinking along the way and keep me on track. Further thanks go to the other tutors on the MA programme, especially to Andrew and James for helping me learn to believe in myself as a teacher and inspiring me to research. My gratitude to my colleagues who agreed to be scrutinised and to the Director of the Business English department at my school for the continued encouragement and support. Heartfelt thanks to Jenny and Rachel for helping me navigate studying and life through this past year and to my family and friends for the continued support and patience through teary phone-calls. To Liz for the Excel help, to Bryony and Sophia for the food parcels and to Anna for homemade cake, encouragement and eagle-eye: Thank you. Finally, my thanks to Lewis for the countless dinners and the teamtalks when I've lost my way. Without you all this research would not have taken place.

Dedicated in loving memory of Louise Micklewright, who sadly didn't stick around long enough to see me in my fancy mortarboard. 


\section{Contents}

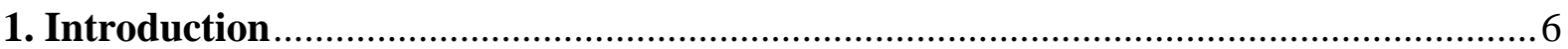

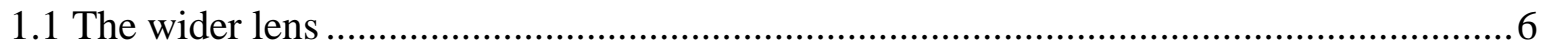

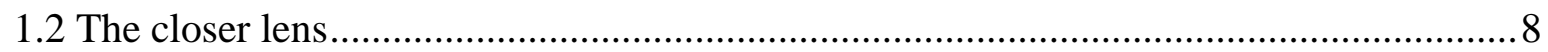

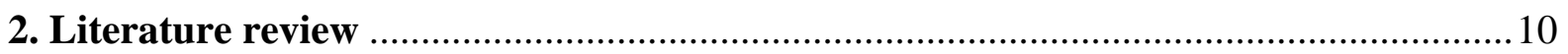

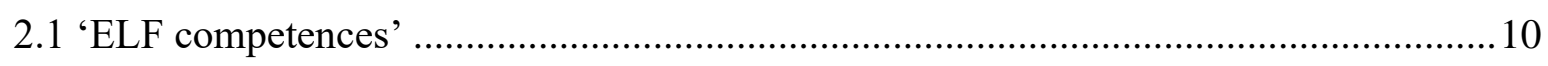

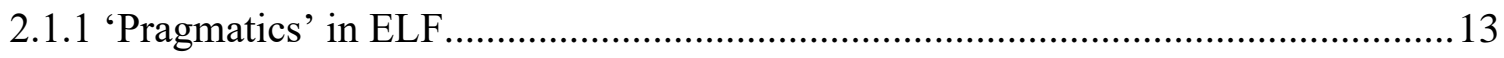

2.1.2 Intercultural Communicative Competence (ICC) ................................................ 16

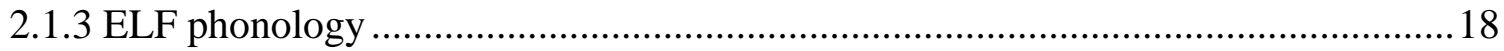

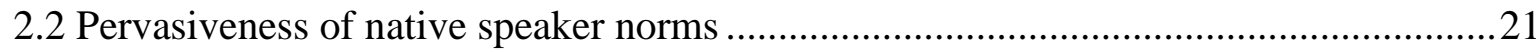

2.2.1 The Common European Framework of Reference (CEFR) ....................................24

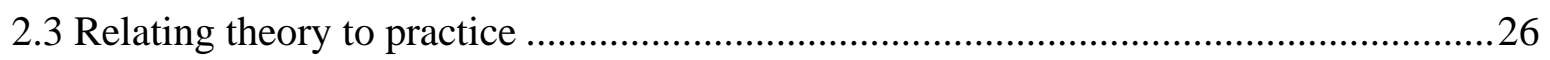

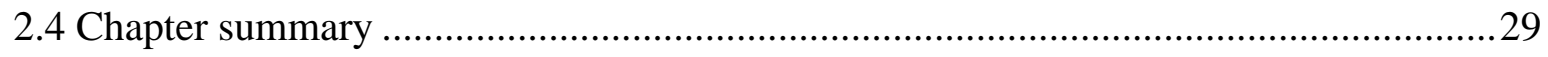

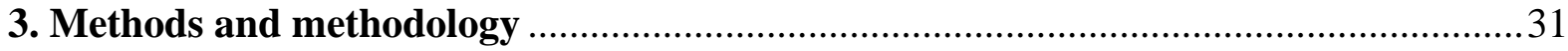

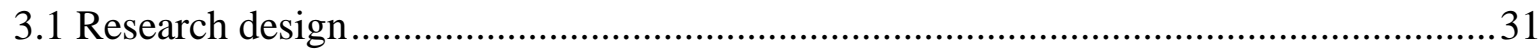

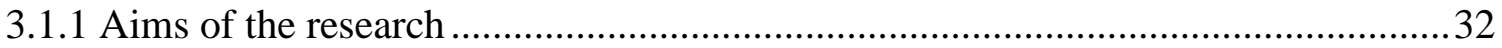

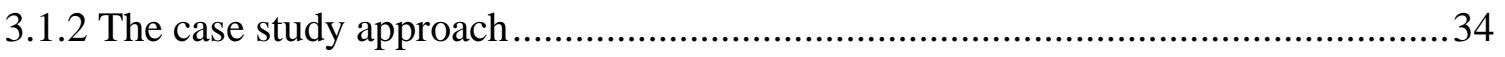

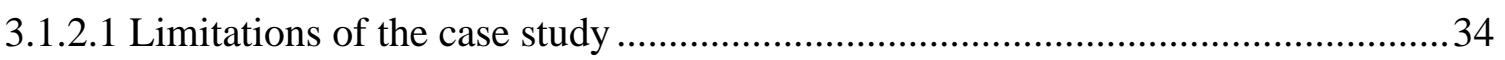

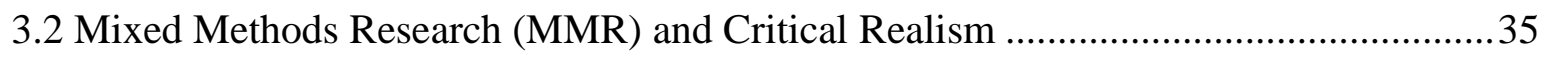

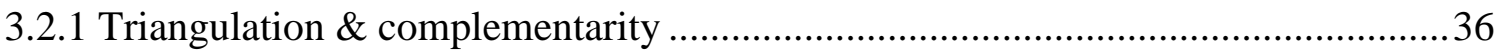

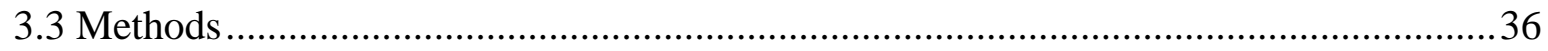

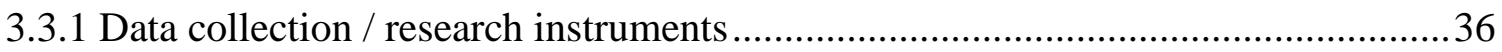

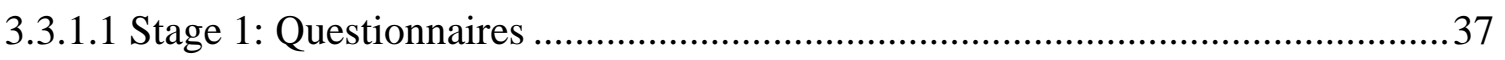

3.3.1.2 Stage 2: Observations and semi-structured interviews .................................... 40

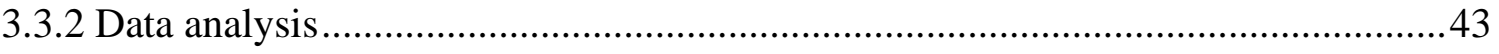

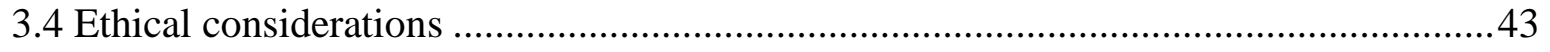

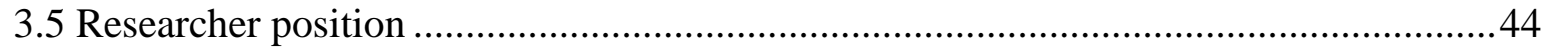

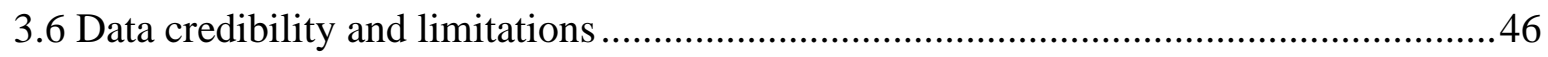

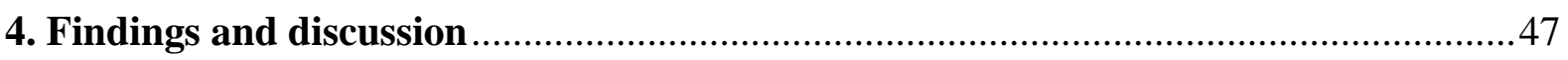

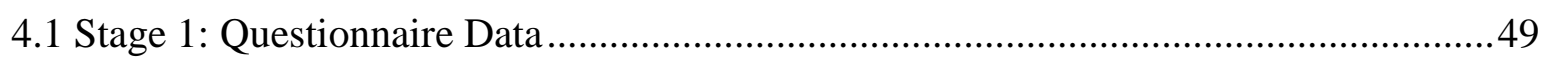

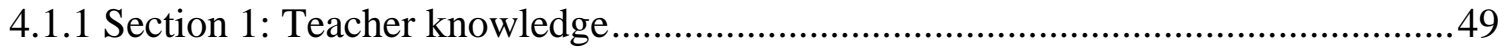

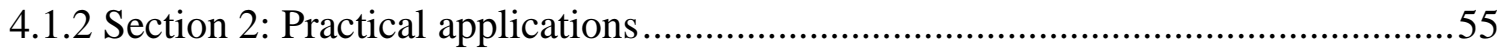




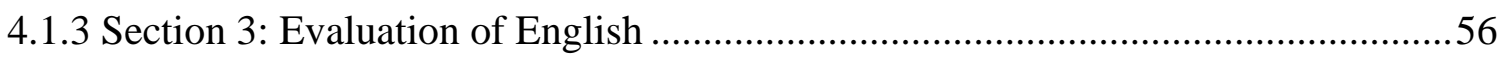

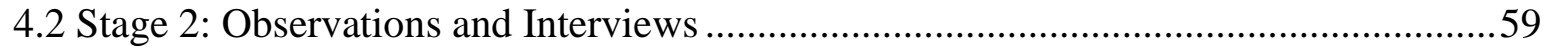

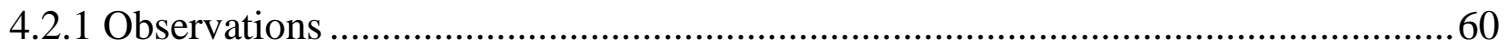

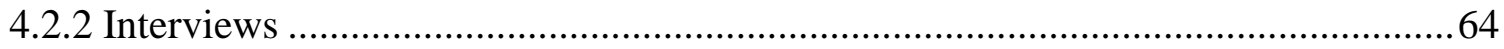

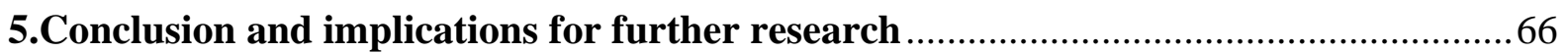

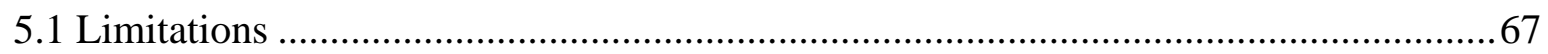

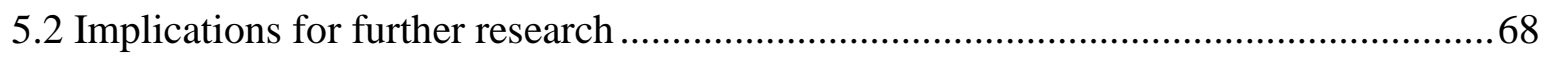

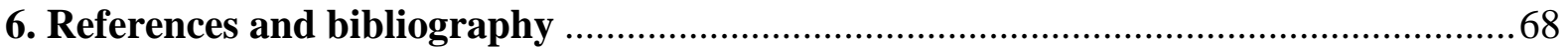

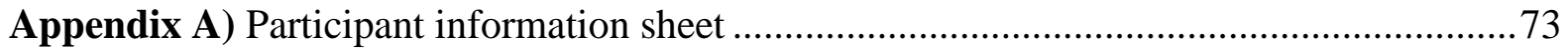

Appendix B) Stage 1 (Questionnaire) consent form ............................................................ 74

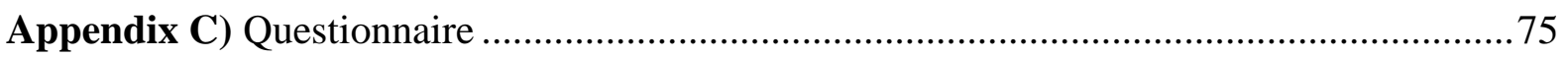

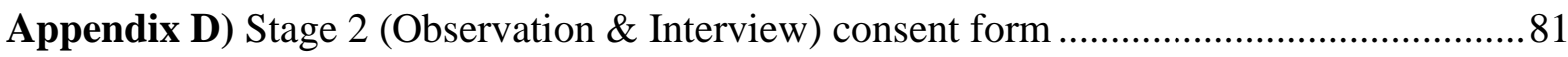

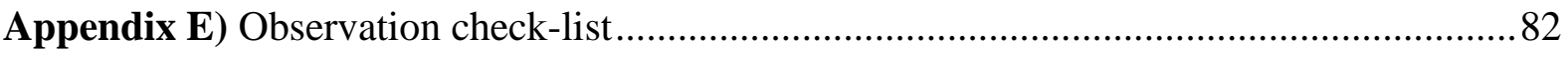

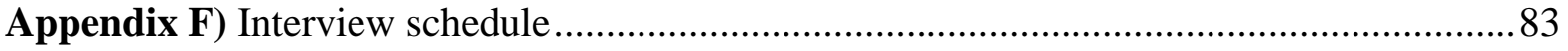




\section{List of abbreviation used:}

$\begin{array}{ll}\text { BE } & \text { Business English } \\ \text { CEFR } & \text { Common European Framework of Reference } \\ \text { EFL } & \text { English as a Foreign Language } \\ \text { ELF } & \text { English as a Lingua Franca } \\ \text { ELT } & \text { English Language Teaching } \\ \text { ESL } & \text { English as a Second Language } \\ \text { GE } & \text { General English } \\ \text { ICC } & \text { Intercultural (Communicative) Competence } \\ \text { L1 } & \text { First language spoken } \\ \text { L2 } & \text { Other languages spoken } \\ \text { LFC } & \text { Lingua Franca Core (Jenkins) } \\ \text { MMR } & \text { Mixed Methods Research } \\ \text { NS } & \text { Native speaker(s) } \\ \text { NNS } & \text { Non-native speaker(s) } \\ \text { RLA } & \text { Recond Language Acquisition } \\ & \end{array}$




\section{Introduction}

\subsection{The wider lens}

In the 'global village' (Ehrenreich, 2011), there is one language you will hear above all others. What you hear may vary lexically, phonologically and even syntactically from villager to villager and it may yet vary from what has traditionally been deigned to be the 'Standard', but English, nonetheless, it will be.

Virally self-perpetuating, English has established itself as the world's 'primary language for international communication' (Kinnock, N. in Graddol 2006:3) with the working figure for the number of English speakers around the world now at around two billion (Crystal 2008:5). Three quarters of this figure are made up of the 'non-native speakers' (NNSs) of English from the Outer and Expanding circles (as defined by Kachru 1985, 1992) that employ a broad range of variants and 'different' (rather than 'deficient') 'Englishes' (Jenkins, Cogo and Dewey 2011:284).

Arguably, the 'spread' -as defined by Widdowson (1997) i.e. not the (necessarily) wilful distribution- of English has come about 'as both [a] consequence and driving force of globalization' (Seidlhofer 2011: no pagination). Whatever the initial reasons for English's rise in global usage it has now cemented its role as a crucial arbiter of international business and trade and it is hard to see how this might now be reversible. Increasing numbers of international corporations, such as Airbus, Daimler-Chrysler, Fast Retailing, Nokia, Renault, Samsung, SAP, Technicolor, and Microsoft in Beijing have mandated English as their company language (Neeley 2012: no pagination). The list of 'multinationals from the nonAnglophone world that have made English their official language' is a long and seemingly continually growing one (The Economist 2014). 
Throughout the history of English language teaching (ELT) linguistic 'standards' have traditionally been set against a target model of Standard English- usually British or American- with native-like competence at the top of proficiency scales (McNamara 2012:201). 'Any non-conformity [from the standard], whether functionally motivated or not, counts as a mistake' (Widdowson 2003:192). Yet for the large and increasing number of English users whose communication occurs in an international context, often with other NNSs, native-like competence or performance is simply unnecessary and a questionable goal.

'Where native competence (whatever that may mean, for it has never been satisfactorily defined) may be an appropriate target for ESL contexts and for foreign languages, it is clearly not the case of lingua francas, of which ELF is the prime example'. (Seidlhofer 2011:9)

This notion becomes especially pertinent when we take into account evidence that some features of NS English (for example, features of connected speech, as discussed later in Section 2.1.3) can have a negative impact on intelligibility. Charles and Marschan-Piekkari (2002, cited in Jenkins, Cogo and Dewey 2011) in fact found that English NS were 'especially problematic in international business communication because they are more difficult to understand' (Jenkins, Cogo and Dewey 2011:298).

The construct of 'English as Lingua Franca' (ELF) - 'any use of English among speakers of different first languages for whom English is the communicative medium of choice, and often the only option' (Seidlhofer 2011:7) - has evolved over the last couple of decades in acknowledgement of this special, transnational, transactional use of the language and has situated itself as an alternative to the traditional paradigms of English as a Foreign or Second Language (EFL/ESL). A steadily growing body of ELF research has developed, primarily out of a number of small and larger-scale ELF corpora, such as the Asian Corpus of English (ACE), the English as a lingua franca in Academic Settings (ELFA) corpus, and the general 
Vienna-Oxford International Corpus of English (VOICE) (Archibald, Cogo and Jenkins 2011:1). Core features of phonology, lexicogrammar and socio-pragmatics that differ from NS norms yet support international mutual ‘intelligibility’ (as defined by McKay 2002:52) have been identified (see Jenkins 2000, 2002; Seidlhofer 2005, 2011; House 2009). It is from the position that these features of ELF, rather than traditional EFL norms derived from NS (now the minority users of English globally), are more suitable goals for users of English in an international business context that I undertook the research described in this document.

\subsection{The closer lens}

After several years teaching EFL and 'ESOL' (English for Speakers of Other Languagesdistinguished here to describe public-funded 'English for the settled community' classes), I have been teaching in the 'Business English (BE)/English for Professionals' department of a private, international English language institution for the past eighteen months,. The learners who attend these small classes (no larger than five students) tend to be professionals already established in their career, usually aged above thirty, with the average stay being around two weeks. For many, as well as (or instead of) liaising with colleagues from English-speaking countries, they are (also) required to communicate with various international colleagues through the medium of English. In this sense, then, they are active users of ELF in their working lives.

It has become increasingly apparent to me that these adult BE learners, regardless of their traditionally measured 'level' of English language competence, have often already been 'successful' users of ELF in their professional contexts: Contracts are obtained, deals are made, negotiations are won. The 'global chatter' of the 'purpose-built' 'rabble' of 'oil-talk' 
or 'commodity talk', rather unkindly described by some as 'blowing the language to smithereens' (Newman 1996:17) does not, twenty years later, appear to have had such a destructive impact, nor, in fact, be so ineffectual or 'atomize[d]' as had been feared. In a similar, Firth (2009) found in his analysis of ELF workplace interaction that despite often highly patent non-conformity to (NS-) Standard English, 'interactants [were] nevertheless demonstrably communicatively competent and skilled commodity traders who enjoy[ed] and cultivate[d] personable and in many cases long-standing acquaintances with one another' (Firth 2009:152).

Graddol, in his British Council-endorsed English Next, defines some characteristics of ELF /EIL education and highlights the shift of emphasis from the 'native-like accuracy' of traditional ELT to 'intelligibility’ (Graddol 2006: 87). Discussing the advent of Global English, he also observes that whereas in the past the UK was a place of pilgrimage for learning English, ELT provision is increasingly being favoured elsewhere in Europe and in Asia, a trend which looks set to continue for the foreseeable future. This point of tension can be identified within many of these BE learners; they are regularly participating in transnational interactions using ELF, however often the very fact that they (or their employer) have selected a British English language school, particularly when an increasing number of alternative and often cheaper options are available, denotes the preference for a NS model.

In view of all of the above, I wanted to investigate BE in practice: What were the current levels of ELF awareness among UK-based BE teachers? Did what I considered to be ELF 'competences' (as discussed in Section 2.1) feature in teachers' evaluations of leaner performance? How pervasive were NS norms in what teachers corrected in class? These were the foundations for the research questions (RQs) that I later developed and based my research on. The RQs and research design are fully outlined in Section 3 (Methods and Methodology), 
but first I would like to take the opportunity to explore, in greater detail, my rationale behind the research and the relevant literature that has informed it.

\section{$\underline{\text { 2. Literature review }}$}

The subject of ELF is an exciting, burgeoning and provocative one. Many books, papers and journal pages have been dedicated to its analysis, description and to the debate over its relevance or even its existence 'as a 'thing”' or “'system”' out there' (Firth 2009:165). There is not enough scope within this document to give a full review of the range of arguments that have been put forward so I will be focusing my attention on those specific areas that have informed my own position and research interests.

In this chapter I will firstly present a perspective of what I am referring to broadly as 'ELF Competences', looking in particular at the cooperatively-driven variability of ELF, the role of 'culture' in ELF interactions and ELF phonology (Section 2.1). I will explore some of the ways in which NS norms still inform our assessments of L2-user performance, with particular emphasis on the Common European Framework of Reference (CEFR) (Section 2.2) and finally I will discuss the importance of relating recent research discoveries to practical pedagogy (Section 2.3). All of the above will be discussed within the broader context of business ELF (sometimes referred to in the literature as 'BELF') and BE teaching.

\section{$\underline{2.1}$ 'ELF competences'}

'Competence' and 'performance' are terms that have also elicited much debate within the ELT profession over the years. 'Competence' has broadened out from Chomsky's (1965) 
original use of the term referring to the internalised grammatical and linguistic knowledge of a person (as opposed its use), and Hymes' (1972) and Campbell and Wales' (1970) suggestion that 'Communicative Competence' need include contextual and sociolinguistic awareness has been widely adopted (Canale and Swain 1980:3-4). This can be seen in the sub-division of specifications in the CEFR for communicative competence to include 'linguistic competences', 'sociolinguistic competences', and 'pragmatic competences' (CoE 2001). The usefulness of the CEFR for describing and assessing ELF is addressed in Section 2.2.1. For now, it is enough to say that if context is a relevant factor in competence, ELF surely represents a unique and potentially amorphous one.

Whilst the systematic use of certain phonological and lexicogrammatical features have been frequently identified and ratified by subsequent research, it has also become apparent that the 'fluidity and flexibility' of ELF is one of its key features (Jenkins, Cogo and Dewey 2011:295). As well as 'non-normative', 'ELF talk' can be broadly seen to be both 'coconstructive' and 'listener-orientated' (Jenkins, Cogo and Dewey 2011:295). ELF-specific pragmatic strategies that facilitate this have been identified, the major one of which being 'accommodation' (discussed further in Section 2.1.1). Whilst this fact of fluidity and flexibility makes the attempt to accurately describe ELF within the parameters of traditional descriptive linguistics a challenging one, I am fascinated by this process- and personorientated perspective to ELF communication and consider it of crucial importance when considering how and what to teach in a BE context.

Within the field of Business ELF (BELF), research so far indicates that intercultural communication skills, as opposed to accuracy to NS- norms, are what drives successful 
communication (Jenkins, Cogo and Dewey 2011:299). In their investigation into international business professionals' perceptions of the success of BELF communication, Kankaanranta and Planken (2010) found that 'clarity and accuracy of content (rather than linguistic correctness) and knowledge of business-specific vocabulary and genre conventions' had a far greater impact on evaluations of success, as well as 'the relational orientation' to the 'variety of cultural backgrounds' that BELF users typically encounter (Kankaanranta and Planken 2010:380). In our globalised economy, where English 'has come to dominate as the language of international business' (Kankaanranta and Planken 2010:381) and interactions are often high stake, linguistic accuracy now carries less weight than accurate content-knowledge and the skill of successfully navigating the intercultural dimension that characterises these interactions.

The 'B' of BELF, according to Kankaanranta and Planken, 'entails the professional domain of internationally operating companies and the people... who constitute that domain'. It is categorised as featuring 'goal-oriented (inter)actions, drive for efficient use of such resources as time and money, and an overall aspiration for win-win scenarios among business partners' (Kankaanranta and Planken 2010:381). If ELF talk is co-constructive, BELF talk is surely a highly finessed example of this and even better suited to Seidlhofer's call (2009), in discussion of the problem of linguistic description of ELF raised by its inherent situated fluidity, to consider applying Wenger's (1998) sociological concept of 'communities of practice' to ELF users. The term 'communities of practice' describes the 'mutual engagement in shared practices, taking part in some jointly negotiated enterprise, and making use of members' shared repertoire' (Seidlhofer 2009:238, citing Wenger- italicised- 1998:72). It can operate as a useful paradigm from which to view this transnational, cooperative and 
successful BELF communication. ELF communication, it has been observed, usually is successful: Misunderstanding and non-understanding are commonly found to occur less frequently in ELF contexts than they do in NS communication (Jenkins, Cogo and Dewey 2011:293).

The broader term of 'ELF competences' can function as a useful umbrella term for this spectrum of macro and micro communicative skills, strategies and features underpinned by the underlying socio-pragmatic processes outlined above. In the following section we will look more closely at some of what I consider to be core ELF competences and therefore highly relevant to BE instruction.

\section{$\underline{\text { 2.1.1 'Pragmatics' in ELF }}$}

The study of pragmatics has generally been situated within the NS paradigm of whichever language is being studied. This is perhaps because in the majority of cases 'the centre of gravity' (Crystal 2008:6) of a language has typically resided with its NSs and it is for this reason that ELF, the primary lingua franca around the world is both unique and fascinating. As mentioned in the Introduction (Section 1.1), nearly a decade ago now, Crystal estimated that 'for every one native speaker, there are now three or four non-native speakers' (Crystal 2008:6); the centre of gravity of English has most definitely shifted.

In this unchartered territory, where the majority of the speakers of English do not share a linguistic and cultural background, the traditional measures of pragmatic competence are less easily applied. Criteria such as demonstrating sensitivity to contextual meaning, implicature 
and inference (Murray 2012:319; Yule 2006:116), upholding (and not threatening) your interlocutor's 'face' needs (Yule 2006:119-120) and observing the specific maxims of Grice's (1972) Co-operative Principle (cited in Yule 2006:129) may rely on a shared linguacultural background and common schematic knowledge. There are, however, a number of key themes that have arisen from research into the pragmatics of competent ELF communication (i.e. not between 'L2 learners') and they will be discussed below.

Above all, research has found ELF talk to be consensual and cooperative in nature (Firth 2009; Jenkins 2007; Pullin 2013; Seidlhofer 2003, 2011).

'As long as a certain threshold of understanding is obtained, interlocutors seem to adopt what Firth (1996) has termed the 'let-it-pass principle', which gives the impression of EIL talk being overtly consensus-oriented, cooperative and mutually supportive, and thus appearing fairly robust.'(Seidlhofer 2003:15)

'Let-it-pass' is one strategy identified by some ELF researchers (although there have been, more recently, some studies with contradictory results; see Cogo and Dewey 2006:66) as a prevalent tendency of ELF interactants to 'ignore or normalise infelicities around syntax, morphology, phrasing, idiom and lexical choice' rather than engage in NS-norm pragmatic strategies such as repair initiation, reformulation or requests for confirmation (Murray 2012:321). Most interestingly, beyond simply overlooking nonstandard production, ELF users often adapt their own speech to imitate those 'infelicities' of their correspondent: 'Oscillation between standard and nonstandard form by the same speakers' (Firth 2009:161) has been observed which, whist on the one hand could be disregarded as unstable interlanguage (from an SLA perspective), on the other it could represent a highly skilful 
adjustment of speech in order to come into closer alignment with the interlocutor (Firth 2009:161) .

'Comity' is the term used by Pullin (2013) to describe the 'solidarity' and 'social harmony' (Pullin 2013:2) frequently observed in ELF, but especially in BELF communication. One key means of achieving comity that has been observed in ELF research is by what is frequently referred to as 'accommodation'. Jenkins (2000) describes accommodation as the bilateral process of speech adjustment, by both listener and speaker, seeking convergence for the purpose of being understood (2000:21) and it is framed within the broader 'Speech (or Communication) Accommodation Theory' (SAT/CAT), originally conceptualised to explain NS ‘accent mobility’ (Jenkins 2000:168-9).

Three directions of convergence have been noted within ELF communication; converging on one another's forms, converging on a 'target-like' form and avoiding certain (usually idiomatic, NS) forms (Jenkins 2006:45-7). In the first case, where learners converge towards each other's forms, 'errors' and 'mispronunciations' may be perpetuated for the purpose of maintaining mutual intelligibility. Rather than failed EFL learner-language this accommodation could be interpreted as high-functioning, interculturally and translinguistically competent ELF usage. This is clearly highly relevant to what is taught in the BE classroom, an argument supported by Seidlhofer's summary that developing learners' communication awareness as well as their strategies for rapport building and accommodating are some of the most valuable things that can be done within the teaching of BE (Seidlhofer 2011:206). 


\section{$\underline{\text { 2.1.2 Intercultural Communicative Competence (ICC) }}$}

BELF is 'intrinsically intercultural' (Pullin 2015:32) by nature of the 'diverse global contexts' (Baker 2011:197) in which it operates. Users necessarily have to navigate cultural as well as linguistic differences during these interactions, overcoming different approaches to and understandings of politeness and genre patterns (e.g. meetings) amongst other things (Pullin 2015:34).

Intercultural Communicative Competence (ICC) is a further, more recent subdivision of the broader construct of Communicative Competence, outlined by Byram (1997, cited in Young and Sachdev 2001:83) that seeks to describe the ability to traverse cultural differences successfully. As with many such terms, viewed from different paradigms and perspectives it, and even the notion of 'culture' itself, have been defined in several different ways, but here it is dealt with in the broadest sense, more akin to what Baker (2011) described as Intercultural Awareness:

'[A] conscious understanding of the role culturally based forms, practices and frames of reference can have in intercultural communication, and an ability to put these conceptions into practice in a flexible and context specific manner in real time communication.' (Baker 2011:202)

In many ways ICC could be regarded as a further example of accommodation, where fluidity of sociocultural (schematic) 'norms' is permitted and adapted to rather than that of linguistic forms. 
There is evidence to suggest that individuals with high ICC, beyond having a basic awareness and tolerance of 'other', actively co-construct a 'third' culture that is 'situated and emergent' in partnership with their interlocutors (Baker 2015), a phenomenon further referred to as a 'relativising C3' by Young and Sachdev (2011:83). ICC is a complex and subtle sociolinguistic skill, yet one that is clearly crucial for navigating the inescapably intercultural nature of (B)ELF communication and according to Pullin (2015), '[t]he integration of an intercultural dimension into Business English curricula...can thus be considered both relevant and necessary' (Pullin 2015:35).

Although the importance of ICC has been officially acknowledged (e.g in the CEFR and various institutional mission statements; see Pullin 2015), materials remain generally lacking. The presence of 'culture' as a topic for discussion within ELT materials has increased over recent years, driven by the inclusion of ICC in the 'curricular guidance in frameworks such as the CEFR' based on 'perceptions that intercultural contact and interchange are greater than ever, necessitating approaches to understanding and brokering difference through effective communication' (Young and Sachdev 2011:81). The way in which culture is dealt with in course-books, however, tends to follow a 'facts-oriented approach in which culture is basically viewed as civilization' that, at its worst, rather than raising awareness of cultural and social differences can simply reinforce stereotyping (Byram and Feng 2005:917). Baker (2015) and Young and Sachdev (2011) have also observed that in General EFL materials any notional coverage of 'culture' only deals with superficial 'aspects of cultural manifestation', avoiding any 'deeper exploration' or 'critical and principled relativisation between world of familiarity and world of difference', the crux of high-functioning ICC (Young and Sachdev 2011:91). 
Teachers, it seems, tend to view ICC as 'problems or constraints' rather than as a resource 'to contextualise and enhance motivation and learning' (Young and Sachdev 2011:82) and actively avoid addressing it within lessons (Young and Sachdev 2011:95). Yet it seems evident that however challenging this area may be to teach, whether that be as a result of limited materials or a wariness of engaging in controversy (Young and Sachdev 2011:95), it is nevertheless a necessary skill for (B)ELF users and BE learners. Research investigating the way in which teachers respond to ICC as a curricular aim is discussed further in Section 2.3.

\section{$\underline{\text { 2.1.3 ELF phonology }}$}

One of the defining attempts to linguistically describe ELF has been within the field of phonology. Jenkins $(2000,2002)$ was one of the first scholars to attempt to identify and establish a set of 'nuclear norms' (Jenkins 2000:2) within ELF communication. Jenkins' Lingua Franca Core (LFC), a proposed 'phonological syllabus' for EIL (2002), was based on her own empirical research into which phonological features may or may not be responsible for the break-down of mutual intelligibility between two NNSs (2002:86). Motivation for the research was founded in the Global English paradigm belief that ELF users have 'no need of a near-native accent and should not be forced to choose between two models or "brands" of English that they may not want to identify with' (Dauer 2005:544) and further supported by increasing SLA research evidence that to achieve a 'native-like' accent is highly unlikely after a certain age (Levis 2005:370). The LFC was therefore suggested as a 'more teachable' 
and regionally appropriate (Jenkins 2002: 83) EIL/ELF alternative to the traditionally taught NS phonological standards, (or 'brands') i.e. Received Pronunciation (RP- 'the upper class British English accent codified by Daniel Jones about 100 years ago') and General American English (GA- 'as described by the American structuralists about 50 years ago') (Dauer 2005:544).

The LFC (Jenkins 2002), as a suggested syllabus for phonological production (Jenkins, 2002, concedes that certain NS phonological features remain important for receptive knowledge) is too long to analyse in detail here, however, some key elements can be summarised as;

- A placing of emphasis on particular segmentals (consonants and vowels) that are seen to most greatly influence intelligibility, notably with the omission of the interdental fricatives $/ \theta /$ and $/ \mathrm{d} /$ and the 'dark 1 ' $/ \mathrm{t} /$.

- Maintenance of contrast between long and short vowel sound pairs.

- Beyond that, regional vowel sounds are 'acceptable if they are consistent'- with the exclusion of substitutions for $/ 3: /$

- Consonant cluster simplification: Addition sounds acceptable, reduction unacceptable.

- Word stress is considered 'unteachable' and unhelpful for EIL communication.

- Intonation to signify attitude or grammatical meaning is avoided as a redundant NS feature.

- However, appropriate use of tonic (nuclear) stress for contrastive meaning is seen as 'critical'.

- All features of connected speech, including weak forms, tend to 'hinder intelligibility'. 
The LFC has provoked many different criticisms relating to its teachability (e.g. Dauer 2002); to the validity of corpus-derived findings and the assertion that occurrence of these identified forms constitutes an ELF phonology as opposed to L2 errors (e.g Kuo 2006); to the fact that it is no less challenging to master (e.g. Wells 2005); to the claimed irrelevance of pitchmovement in ELF (e.g. Pickering 2005) and to the 'fallacy of the absent native speaker' (Prodromou 2007a:410). A further, common criticism of the LFC has been that it is untenable as a complete phonological syllabus replacement:

'The fallacy of much native-driven corpus linguistics was that description and prescription were assumed to be the same thing .... Jenkins may be committing the same fallacy.' (Prodromou 2007a:410)

The mistake of many of these criticisms, particularly the latter, is that Jenkins had never intended for the LFC to function as a prescriptive pronunciation model, but rather as 'a set of guidelines that would be important for intelligibility on some occasions not others, depending, in particular, on who was speaking with whom' (Jenkins, Cogo and Dewey 2011:288). Something that seems to have been crucially overlooked in a lot of the discussion of the LFC is its reliance on accommodation for it to be a successful model. Jenkins was one of the first to identify the role of accommodation within ELF and even on the micro level of phonology what seems, again, to be of utmost importance is the 'online' (Jenkins, Cogo and Dewey 2011: throughout) relational element to successful ELF communication. The distinction between what knowledge is important for receptive and productive use (Jenkins $2000,2007)$ is also highly relevant to how pronunciation is presented within BE instruction. If the phonological teaching and learning load can be reduced by removing features that are non-essential or less critical for mutual intelligibility and prioritising those which are, that can only be a useful thing. 
It is my firm belief that all of the 'ELF competences' discussed above are highly relevant to the teaching of BE. This is not to say that these communicative features should take complete precedence over more traditional ELT areas of focus such as grammar, lexis or traditional phonology- especially when receptivity is considered- however it does seem that if the features and competences described in this Section (2.1) are not paid adequate attention in our BE teaching we risk not providing our learners with a large, if not the larger, portion of the skills they will require to succeed in their ELF interactions. In Section 2.3 the ways in which theory does and doesn't inform pedagogical practice will be explored, but first let us discuss (in the following Section 2.2) the current NS-norm referenced model of ELT that any ELF-orientated approach finds itself in opposition to.

\section{$\underline{\text { 2.2 Pervasiveness of native speaker norms }}$}

The traditional model of EFL that has dominated ELT over the past century has seen linguistic 'standards' modelled on the NS norms of 'Standard English'. In placing great importance on NS standards and the awareness of native 'culture', the EFL model essentially 'positions the learner as an outsider, as a foreigner; one who struggles to attain acceptance by the target community'(Graddol 2006:82).

Proponents of the World Englishes (WE) paradigm have sought to redefine the parameters of 'English' from its being viewed as a monolithic entity where one 'standard' form reigns, to a 
'plurilithic' one (Hall 2014). The idea that any named language exists as a 'real world object' (Hall 2014:378, citing Pennycook 2007) is seen as a (necessary) fiction. Instead;

'[t]his view sees English, and all other 'named languages', not as singular reified entities... codified in books and dictionaries, but as dynamic sets of overlapping phonological, grammatical, and lexical resources, stored in millions of individual minds, which interact in multiple communities and cultural practices.' (Hall 2014:379)

Once you begin to validate the many different Englishes that exist the continued maintenance of NS norms as a target starts to become questionable practice, particularly given the imperialistic history of its initial spread (see Phillipson 1992). '[T]he economic and ideological motivations behind the valorization of standard English and the authority of the native speakers in language pedagogy' (Canagarajah 2005:940) need to be disentangled from genuine pedagogical rationale. Much debate over such ideas and discussion of Critical Pedagogy (CP) have taken place over the years (see, for example, Canagarajah 2005; Pennycook 1994; Phillipson 1992) and there is too little space here to do its exploration justice. Let it suffice to say that for the third of the world's population who speak English (Crystal 2008:5), it seems reasonable to assert that the so-called standard norms of the population of a tiny (yet once colonial) island in the North Atlantic, adhered to by very few of its 'native speakers' anyway (Timmis 2002), are no longer a relevant or reasonable linguistic target.

If NS norms aren't a relevant (or achievable) goal, then what should students be encouraged to aim for? This is where the argument for intelligibility over accuracy comes in, with Jenkins' $(2000,2002)$ LFC offering a response to the phonological issue (as discussed in Section 2.1.3), and Seidlhofer $(2003,2005)$ to that of lexicogrammar. Based on analyses of 
dedicated corpus data, emerging patterns of lexical and grammatical forms have been identified, although more recently the research has shifted onto the "communicative functions that give rise to these features' (Jenkins, Cogo and Dewey 2011:289) (as discussed in Sections 2.1 and 2.1.1). Features that have been identified as commonly converged upon in ELF talk include:

- Dropping the third person present tense $-\mathrm{s}$

- Using the relative pronouns who and which interchangeably

- Uncharacteristic of NS norms use of definite and indefinite articles (omission and insertion in 'irregular' places)

- Simplified tag questions (e.g isn't it? / no? in place of shouldn't they?)

- 'Over-use' of 'redundant' prepositions (e.g. We have to discuss about...)

- 'Over-doing' explicitness (e.g. black colour as opposed to black)

- Substituting infinitive clauses with that-clauses

(Jenkins, Cogo and Dewey 2011:289-290, citing Seidlhofer 2004)

Whilst these forms may not interfere with intelligibility (or may perhaps even support it) there is still the potential for stigma to be attached to their production based on the view that they exemplify failed or fossilised interlanguage (Jenkins, Cogo and Dewey 2011:290). The primacy of NS-norms is dogged and rife and attached to the use of them comes significant status and 'culture capital' (as defined by Bourdieu 1986). Regardless of how prevalent and effective 'ELF forms' are in international business communication (Firth 2009 discussed in Section 1.2; Kankaanranta and Planken 2010 discussed in Section 2.1), to teach or to encourage them is another matter. A key factor appears to be the underlying, driving process of accommodation, both in terms of converging towards a central form and of adjusting ones 
receptive tolerance of different forms. This is something that can perhaps be addressed in the classroom more easily, without any potentially negative impact on the learners.

Only a little research has yet been done into the perspectives of teachers and learners in relation to ELF and linguistic targets (Dewey 2011, 2012; Maley 2009; Timmis 2002). Of the little that there has been, the results seem to indicate, perhaps unsurprisingly, a general preference for NS-norm-centric learning (Jenkins 2007; Prodromou 1992, in Maley 2009; Timmis 2002). It is notable, however, that in Timmis' survey-research across 45 countries, whilst learners tended to favour the NS model of English, teachers showed a preference for 'accented intelligibility' (i.e. retaining the 'accent' of the learner's home country) as a more desirable goal (Timmis 2002:242-3), whereas they demonstrated a marked preference for NS lexicogrammatical norms. Teachers are more willing to tolerate phonological variety, but whether this is truly based on the belief that 'accent' positively denotes character and personality (as many of the answers given in the survey suggested) or on the awareness that to achieve a native-like accent is unlikely after puberty (Levis 2005:370), we cannot be sure.

\subsubsection{The Common European Framework of Reference (CEFR)}

A plurilithic orientation to English, with its intrinsic acceptance of variety, lends itself to a functional focus of what can be done or realised with the language as opposed to a focus on achieving (NS-norm informed) accuracy. This corresponds well with 'the broader functional notion of communicative competence' (Hall 2014:376) that the CEFR has attempted to describe with its set of 'can-do' statements that learners' performance is measured against. 
The argument has been made however, (albeit largely by those in favour of the recognition of an accepted description of ELF) that the CEFR continues to permit the native speaker to 'lurk at the top of the proficiency scales' (McNamara 2012:201).

'It is clear that the concept of English as a lingua franca communication does not inform these descriptors. In term of comprehension, the interlocutors are assumed to be native speakers, as the references "at fast native speed" and "a good familiarity with idiomatic expressions and colloquialisms" make clear; and the responsibility for successful communication is held to lie entirely with the non-native speaker.' (McNamara 2012:200)

This addresses a contradiction that runs throughout the entirety of the document: Its aims are explicitly stated in its opening chapter as being in accordance with a 'plurilingual' perspective, rejecting an 'ideal native speaker' model for one that favours a more diversified ‘linguistic repertoire' (Pitzl 2015:99, citing CoE 2001), yet its descriptors repeatedly reify NSs.

The CEFR is relevant, as whilst it was first commissioned by the Council of Europe as a general framework for the learning of all languages, it has now 'come to frame education policy' for ELT and inform testing within Europe and now even beyond (Hynninen 2014:294). It also forms the basis of formative and summative assessment within the school where my research was carried out (described in Sections1.2 and 3.1.1). Aside from the NS focus that doesn't support ELF goals, the CEFR's purposefully 'context-free' descriptors bring into question the 'applicability of the CEFR to specific contexts' (Hynninen 2014:295); a problem in terms of BELF, at least, when BE is often considered as simply another type of ‘English for Specific Purposes' (ESP) (Widdowson 1997:143). 
More subtly, but perhaps more crucially, '[t]he work of achieving and maintaining understanding in order to sustain a social relationship is presented as being exclusively the responsibility of the language learner' (Pitzl 2015:102). Emphasis is consistently placed on the learner-speaker not causing misunderstanding (Pitzl 2015). This attitude to understanding as a one-sided, receptive affair directly contradicts the great body of ELF research that indicates that ELF communication is co-constructed, cooperative and highly-negotiated (as discussed in Sections 2.1 and 2.1.1). Whilst there is much to be said about the CEFR in its favour, it is clearly not a suitable framework in the context of (B)ELF; possibly because it was originally designed as a point of reference for foreign language learning (Hynninen 2014:294) and English, functioning as a lingua franca, has gone well beyond that. In view of its unique position and function, I would argue that not only is the CEFR not at all suitable for the measurement of ELF performance, but that there is a great and urgent need for a set of competence descriptors for ELF specifically.

\subsection{Relating theory to practice}

It has long been observed that regardless of how ground-breaking any new research may be, or how water-tight its results, there is often still a considerable distance to travel before it affects any measurable influence on practice. This phenomenon does not belong exclusively to the field of ELT; law, medicine and education more broadly also suffer the same slow trickle-down of theory into practice (Ellis 2009:184). One means of addressing this division has been to call for teachers to participate in 'action research' (Ellis 2009:189); research within their own, and therefore familiar, domains with what one would expect to be resultant higher 'ecological validity' (Ellis 2009:191). Whilst this is a valid and useful way of engaging teachers with the concepts of researching pedagogy and critical evaluation of 
method and methodology within their own context, and may provide useful, localised data, we cannot realistically expect teachers to also be experts in all of the many facets that constitute and inform ELT; breadth as well as depth is necessary.

A more reliable means of addressing this might be to ensure course-books are designed around current, research-derived pedagogical theories. In terms of incorporating ELF research into pedagogy, one of the most common criticisms (from both sides of the ELF argument) is because of a lack of core descriptive ELF features, there is a dearth of useable material from which teachers can build lessons (see Maley 2009; Pennycook 2007b; Seidlhofer 2003). Timmis (2012), discussing the way in which corpora research into spoken language feeds into its teaching, reports that while some 'research has filtered through to coursebooks [sic]', it has done so 'in restricted ways and with wide variation between coursebooks in how systematically spoken language is treated' (Timmis 2012:519). A cynic may also take the view that when it comes to ELF research it may be less than surprising that the NS-norm-driven publishing industry of ELT materials might be slow to respond.

Interestingly, it appears there are other factors that affect the ways in which teachers apply theory to their practice, beyond the difficulties of bridging the gap between declarative and procedural knowledge (Ellis 2009) and the general lack of relevant materials. Young and Sachdev (2011), when investigating teacher beliefs and attitudes in relation to ICC, found that even when lack of materials was not an issue (the teacher-participants in question used a wide range of easily-accessible and relevant realia) 'an apparent disparity emerged between most teacher-participants' beliefs and their practices', i.e. they 'expressed a broad general 
view that an intercultural approach may be successful and appropriate, but seemed unable or unwilling to put it into practice (Young and Sachdev 2011:95). In their conclusion the pair observe that very little reference to ICC is made in many of the formal, internationally recognised ELT training programmes and surmise that a lack of adequate teaching training may be a significant contributing factor in the lack of uptake among teachers (Young and Sachdev 2011:95). A similar stance was taken by Dewey when designing his 2012 research into teacher attitudes and awareness of ELF, discussed below (Section 2.3.1).

Perhaps the ideal situation, in what has been referred to as the 'post-method' era of ELT (Kumaravadivelu 2006, cited in Ur 2013), would be for teachers to develop their own 'situated methodologies' (Ur 2013:470) that are informed by an understanding of both more general pedagogical principals and practice and of their specific context. In this context;

'Sources of teachers' theories and beliefs about teaching are primarily their own reflection on practice... but enriched by the literature on pedagogical and educational issues in general, sociology, cognitive psychology, and so forth, as well as linguistics and SLA research.' (Ur 2013:470)

Many of the key ELF competences identified above (such as ICC and accommodation) are as much related to the study of cognitive and social psychology as they are to that of linguistics. The task of equipping teachers with sufficient general educational knowledge as well as ELTspecific pedagogical skills seems to fall to the teacher educator (see Ellis 2009), yet currently they seem to be falling somewhat short, especially where ELF in concerned (Dewey 2012; Ellis 2009; Jenkins 2006; Young and Sachdev 2011; Sifakis 2007). 
At the centre of Dewey's $(2011 ; 2012)$ research into teacher awareness of ELF was the belief that in order to address the incorporation of 'an ELF-orientation in current practice' (Dewey 2012:142) teachers must first undergo a fundamental 'rethinking' of how they conceptualise language(s), English and ELT, based on the premise that ELF research findings 'run contrary to received wisdom in ELT professional discourse' (Dewey 2012:142). This is also a theme explored by Sifakis (2007) who suggests that paradigm shifts are required on both individualconceptual and ELT-pedagogical levels challenging, among many other things, implicit 'imperialistic' notions of NS ownership and primacy of NS norms (Sifakis 2007:358). Crucially, Sifakis makes the claim that 'mere exposure to and awareness of the relevant literature will not be enough' to catalyse the necessary shift in teacher consciousness; serious 'critical reflection' is required (Sifakis 2007:358).

What we begin to reach here is an awareness of the importance of the nexus between teacher beliefs about language, about 'English' per se, and an ontological 'reality' of 'English' as a vivid, nebulous, yet scientifically and empirically 'measured' 'thing' in its many and varied contexts. It may not be sufficient to simply present teachers with findings from ELF research if the findings themselves, 'incongruous with existing ideas about language' (Dewey 2012: 143) create cognitive dissonance. The relevance of 'teacher cognition' (Borg 2003) to pedagogical practice is explored in greater depth in Section 3.1.

\subsection{Chapter summary}

While divisive within the field of ELT, ELF is not going anywhere. In a postmodern, globalised world where English is used by millions and as the primary lingua franca of 
international business, thorough exploration as to how the language is used in these contexts is surely merited, with any findings necessarily relevant to ELT pedagogy in general, but especially to BE instruction. Through this review of the relevant literature it has been observed that beyond the oft discussed lexicogrammatical and phonological features of ELF discourse, that have been identified through corpora research, there also appear to be some key sociolinguistic features of ELF talk (e.g. ICC, accommodation and its inherent, contextually relevant, dynamic variability) that underpin linguistic choices made and greatly increase the chances of successful transnational communication.

Whilst ELF research findings are steadily building, the impact that these are having on pedagogical theories and classroom practice appear to be minimal with 'most teachers of English [...] sublimely unaware of the ELF debate' (Maley 2009:196). ELF and ICC have been acknowledged as valid constructs and aims in some of the more influential international syllabi and frameworks (such as the CEFR and the DELTA training criteria), yet coursebooks, on a whole, continue to perpetuate a NS-norm of 'Standard English'. Beyond that, we have seen that even when teachers have access to appropriate materials and an awareness of the above concepts, there often is a discrepancy between teachers' (stated) beliefs and their teaching practice.

With all of the above in mind, I subscribe to the following sentiment:

'It is therefore paramount that we consider what ELF means with regard to teacher knowledge about language and language teaching methods. This requires systematic long-term empirical engagement with practicing teachers. 'Dewey 2012:143' 
It is my firm belief that BE learners are prime candidates for ELF-orientated ELT. It is also clear that BE teachers are uniquely exposed to functioning, ELF-using, international business professionals and may, as a result, have a different perspective to that of GE teachers with regards to ELF. Based on the above, I decided to investigate the levels of ELF awareness and associated teacher-beliefs of practicing BE teachers within a small case-study. Research questions, design and instruments are all outlined in the following section 'Methods and Methodology' (Section 3).

\section{Methods and methodology}

The following section will discuss the methods used in the collection of data and the rationale for choosing them. I will outline the research aims, describe the research instruments and outline my own position in relation to theories that inform the search of 'knowledge'.

\section{$\underline{3.1}$ Research design}

In a study that sets out to investigate the awareness and attitudes of teachers with regard to a specific construct (ELF, in this case) it is worth reminding ourselves at the outset why it is that these things matter. The starting position for this investigation is founded on my belief that teacher knowledge and pedagogical practice are, in the first place, informed by the beliefs about both language and the world around them that teachers, knowingly or unknowingly, hold. 'Teacher cognition', itself rooted in a Cognitivist paradigm for understanding human behaviour and thought, has been the subject of mainstream socio- 
educational research over the past three decades (Borg 2003:81). Its core assumptions that 'teachers are active, thinking decision-makers who make instructional choices by drawing on complex, practically-oriented, personalised and context-sensitive networks of knowledge, thoughts, and beliefs' (Borg 2003:81) are now well accepted. This study seeks to investigate that core teacher-cognition within the framework of a contextualised case-study of a small group of BE teachers.

\subsubsection{Aims of the research}

Dewey's study (2012) explores the impact of ELF research and theory on pedagogy and language-teacher training. The results of his research indicated that among his participants, all of whom were enrolled on MA programmes in either TESOL/ELT or Applied Linguistics within the UK, there was a good level of awareness and basic understanding of ELF and yet, interestingly, a 'fundamental ambivalence' towards it in terms of attitudes (2012:167).

Whilst encouraging in terms of apparent levels of teacher awareness of ELF, an important factor in this study is that all participants had had access to post-graduate ELT / Linguistics instruction. One of Dewey's key aims of this study was to gauge the extent to which ELF theory and research inform ELT-teacher training, with DELTA syllabus guidelines having been updated in 2008 to include an ELF component (Dewey 2011:214). Clearly, as has been my experience on my MA in ELT, ELF awareness is increasingly being encouraged among student-teachers at a post-graduate level of study. What there does not seem to be a great deal of research into however, is the extent to which in-service ELT teachers are ELF-aware and to what extent these concepts are operationalised within the classroom. Young and Sachdev (2011) make a similar observation in their introduction to their investigation of teacher beliefs around ICC: 
'Research into language teaching has been generally neglectful of the beliefs and practices of experienced language educators at least relative to the amount of research attention given to pre-service or inexperienced teachers.' (2011:83-84)

With this in mind and with the belief that ELF awareness is all the more relevant for teachers of BE, I decided to conduct my own small investigation into the levels of ELF awareness and the teacher cognitions associated with it within a sample group of experienced BE teachers. The participants were drawn from the dedicated BE department of an ELT school, where I also work, in the South of England, UK.

My aims were consolidated into the following research questions:

1. What are the current levels of ELF awareness in a set of BE teachers in Brighton?

2. How pervasive are Native Speaker (NS) norms in what and how these teachers correct in class?

- Are 'ELF competencies' such as accommodation strategies, 'letting it pass', LFC phonology and ICC being taken into account?

- Is intelligibility valued (and encouraged) above (NS-norm defined) accuracy?

- To what extent do CEFR criteria influence their evaluation of student language competence? 


\subsubsection{The case study approach}

Case-studies have been defined by Yin (1989 in van Lier, 2005:196) as 'an empirical inquiry that investigates a contemporary phenomenon within its real-life context; when the boundaries between phenomenon and context are not clearly evident; [and in which ] multiple sources of evidence are used'. Given that this study is interested in exploring the attitudes and awareness of practicing BE teachers and the way in which these inform their teaching, a case-study approach seems appropriate. Multiple methods for sourcing of evidence were indeed selected, as will be outlined below in Section 3.2. Given the time constraints imposed on this study, choosing to apply a detailed focus to a specific, bounded sample group as opposed to, for example, attempting a large-scale quantitative survey of inservice BE teachers, seemed the most effective way of procuring a clear snap-shot of teacher awareness and beliefs around ELF.

\subsubsection{Limitations of the case study}

Whilst case-studies have, at times, significantly contributed to the development of (S)LA theories (e.g. Schmidt's study of Wes, 1983, and Schumann's of Alberto, 1978), they have also 'often been accorded less status than more rigorously controlled experimental or processproduct studies' (van Lier 2005: 198). Criticisms generally centre on the limitations of the generalisability of results (Bell 2010:9), yet there is a richness of data that can be mined from this contextually-situated type of research. Taking the view that language learning and teaching are complex and multi-dimensional phenomena that, due to their nature of being human pursuits, are socially constructed and therefore socially situated, the case-study approach seems a relevant means of investigation. 


\subsection{Mixed Methods Research (MMR) and Critical Realism}

One means of increasing validity- 'whether an item or instrument measures or describes what it is supposed to measure or describe' (Bell, 2010:118-9) -and credibility in case-study research is to broaden the means of its enquiry. MMR, the blending of a variety of different methods from differing paradigmatic backgrounds, has been put forward over recent years as a 'third methodology' and as an alternative to purely qualitative or quantitative approaches to research that can be seen to have its roots in a Critical Realist perspective (Mehdi Riazi and Candlin 2014:138-140).

Critical Realism is a branch of philosophy that, first and foremost, sees the world as existing 'independently of our knowledge of it' (Sayer 1992:5-6). Within this is the belief that 'things' can be measured or observed, although our perceptions can be expected to shape our understanding of them. Within this framework, it is seen that ' $[\mathrm{s}]$ cience or the production of any other kind of knowledge is a social practice....the conditions and social relations of the production of knowledge influence its content.' (Sayer 1992:5-6). Not only does this paradigm support a MMR approach, but it also correlates with the view that teachers' perceptions of the world influence their conceptualisation of it (as discussed in Section 2.3.1 and 3.1). By selecting a range of quantitative and qualitative methods (questionnaire, interviews and observations) I hoped to be able to capture a more multi-dimensional picture of the sample group in question and to offset some of the inherent subjectivity that will necessarily come into my interpretations of the data by exploring the issue from a number of angles. 


\subsubsection{Triangulation \& complementarity}

A further benefit of applying a MMR approach is that, by its nature of generating multiple sources of data, it lends itself to triangulation. Triangulation, the term given to the crossreferencing of findings with the aim to strengthen (or disprove) results (Bell 2010:118), originally referred to a blend of solely qualitative methods (Mehdi Riazi and Candlin 2014:144) and cannot be truly considered a sound means of corroboration if different constructs are being dealt with by the different methods (Mehdi Riazi and Candlin 2014:154). A further option then is to seek 'complementarity', where 'quantitative and qualitative results may be drawn upon to interpret different aspects of the phenomenon' as if 'peeling the layers of an onion' (Mehdi Riazi and Candlin 2014:144). In either case, a MMR approach facilitates this kind of cross-referencing of results and depth-building.

\subsection{Methods}

This case study takes a sequential quan $\rightarrow$ QUAL MMR design (as defined by Mehdi Riazi \& Candlin 2014:146-7), where initial quantitative data from a set of questionnaires leads to a deeper qualitative exploration within a sub-sample of questionnaire respondents, with the main emphasis being on the qualitative component. The precise research instruments used are described below.

\subsubsection{Data collection / research instruments}

As mentioned earlier, inspiration for this study comes from Dewey's research (2012) in which he administered questionnaires to a sample group of MA TESOL / Applied Linguistics student-teachers. I decided that rather than completely devise my own questionnaire, it would 
be more useful to base my questionnaire on his, having already been validated, with the addition of a few adjustments (outlined below in 3.3.1.1) that better suited my specific research aims. In terms of my research aims, RQ2 seeks to discover the extent to which NS norms influence what is corrected in the BE classroom and how. I felt that the third section of his questionnaire in particular, 'Evaluation of English' (see below, 3.3.1.1) had the potential to give a good picture of the extent to which NS norms inform judgements of 'correctness' in a manner that was closer to classroom practice than directly asking participants what they think about NS norms.

The questionnaires formed the first stage of my research, with the second, more qualitative stage that followed including both observation and short follow-up interviews with the observed participants. I felt it was important to observe at least some teachers in situ when considering RQ2 (How pervasive are NS norm in what and how these teachers correct in class?) as what is done in practice may sometimes differ from what teachers think they would do in given, hypothetical situation.

\subsubsection{Stage 1: Questionnaires}

Dewey's questionnaire was described in his 2012 article as containing three sections. I found two of these to be relevant to my research aims and so chose to replicate them with some minor adjustments. These are represented in Sections 1 ('Teacher Knowledge') and 3 ('Evaluation of English') of my questionnaire, outlined below and contained within the full questionnaire provided as Appendix C. 
The questionnaire was emailed out on $11^{\text {th }}$ July 2016, along with the Information Sheet (Appendix A) and the Consent form (Appendix B- both also discussed below). The email, inviting recipients to participate, was sent via the Director of the BE department to fifteen teachers identified as having taught BE within said department. A further three teachers were identified in the main school as having taught group BE classes whenever there was enough student demand for these classes to be run and these were sent the same email by the Director of the main school. Participants were initially requested to respond within one week, but due to slow response the window was extended to the $22^{\text {nd }}$ July. This decision was taken in consideration of Bell's warning that it is often the case that those who do not respond are those whose answers differ from the norms (2010: 153, citing Moser and Kalton 1971).

Prior to distribution, the questionnaire was initially piloted with one General English (GE) teacher from the main school in order to check the design. The feedback from this teacher was that the questions were very clear and the questionnaire easy to complete. No amendments to the design were necessary, however, the digital format of questionnaire was changed from a .pdf document to a Word .doc in order to improve accessibility.

Section 1) 'Teacher knowledge' (measuring awareness): The opening section includes five open-ended, short-answer (McKay 2006.:37) questions, where respondents are asked to describe what they understand by the following terms; a) English as a Global language, b) World Englishes, c) English as a Lingua Franca, d) Intercultural Competence and e) Accommodation (strategies). Terms $a, b$ and $c$ were reproduced from Dewey's questionnaire whilst the final two $(d, e)$ were added to more 
fully support the research aims, in particular with relation to the 'pervasiveness of NS norms' as expressed in RQs 1 and 2. It is also my view, as discussed in Section 2.1, that ICC and Accommodation strategies are essential aspects of ELF, and so important factors when seeking to measure ELF awareness (as in RQ1).

\section{Section 2) Practical applications (measuring opinions on pedagogy in practice)}

This section presents respondents with a longer open-ended question that invites them to give their opinions as to the relevance of the terms (and constructs) addressed in Section 1 to their BE teaching practice.

\section{Section 3) 'Evaluation of English' (measuring attitudes toward linguistic features)}

In this final section, respondents are asked to rate a series of ELF lexicogrammatical forms in terms of correctness, acceptability, intelligibility and importance (in terms of needing to be 'corrected' in the classroom). This directly replicates a section of Dewey's original research, using the same sample utterances selected from ELF corpora (2012:149) with the exception of one ('g) I didn't finish reading the book yet') which 'was invented and...designed to represent a commonplace characteristic of standard American English' (Dewey 2011:217).

It was this feature of the original questionnaire that I had considered to have the most potential to support my own investigation. As dimensions by which to evaluate an 
utterance, 'correctness' and 'importance to be corrected' reflect the on-the-spot 'judgement-calls' teachers have to make on a moment-by-moment basis, guided by both learner needs and proficiency level. Evaluating an utterance in terms of 'acceptability' begs the necessary question- according to whose or which standards? In terms of 'intelligibility', it could be argued that as learners are (B)ELF users, if their utterance is intelligible, it need not be corrected in class (see Section 2.2 for a discussion of NS norms, accuracy and 'correctness'). I was therefore interested to see whether this kind of thinking was present or not among the sample group of BE teachers.

Respondents were invited to rate each utterance in relation to the four dimensions described above using a Likert scale (Bell 2010:146). For greater clarity and consistency I chose to amend the scale by providing five terms ('not at all', 'not very', 'neutral', 'somewhat' and 'absolutely') and assign them to the numbers -2 through to $(+) 2$, with 0 representing a 'neutral' view. I had felt that 'neutral' was an important stance to include and specify, rather than, for example, the central value of 'undecided' often found on a Likert scale as this conveys more of an ideological position than an uncertainty.

\subsubsection{Stage 2: Observations and semi-structured interviews}

Of the questionnaire respondents who had indicated that they would be willing to participate in the second stage of the research, two were selected. I had wanted to select teachers representing differing ends of the continuum of responses however only $42 \%$ of respondents 
(five of twelve) had given their consent to be contacted for inclusion in Stage 2 and teacher availability also had to be taken into account.

The two teachers eventually chosen to participate in the observations and interviews were assigned the IDs 'Teacher 4' and 'Teacher 12' (based solely on the order of questionnaire return). Both were male, NSs, early 40s and with ten and fourteen years of teaching experience respectively. Teacher 4 had taught in Mexico, Spain and England and Teacher 12 in Latvia and England. Teacher 4's responses in Section 3 had fairly consistently deviated from the sample norm in that he frequently evaluated utterances as 'not at all correct' (see Results in Section 4), whilst maintaining higher-than-average evaluations of intelligibility and acceptability. Teacher 12, on the other hand, frequently rated utterances as 'somewhat' correct when his colleagues were, in general, evaluating the same utterances as 'not very' or 'not at all' correct. Teacher 12's responses were also interesting in that he almost consistently rated utterances as 'somewhat important to correct in class', whereas Teacher 4 maintained an almost exclusively 'neutral' stance to the question of importance to be corrected. Both of these teachers appeared to hold interestingly different perspectives on the above dimensions as well as on the relevance of ELF to pedagogy in practice so seemed to be good candidates for further investigation.

The focus of the observations was on what is corrected (and /or encouraged or instructed) in class and how, with a particular emphasis on phonology (in relation to the LFC in contrast to NS norms), lexicogrammar (Seidlhofer's model of ELF usage, as exemplified within the sample utterances of Section 3 of the questionnaire, in contrast to NS norms) and 'ELF 
competencies' (i.e. accommodation strategies; 'letting it pass' etc.) as outlined in the introductory literature review. In order to achieve these aims an Observation Checklist was used (see Appendix E).

A further aim of the observations was to try to measure any correlation between the attitudes expressed in the questionnaire stage, and pedagogy in practice. As Bell (2010:191) reminds us, '[o]bservation can be useful in discovering whether people do what they say they do, or behave in the way they claim to behave. However, observation also depends on the way people perceive what is being said or done'. A rationale for conducting the interviews after the observations as opposed to before was not only to reduce the potential influence on 'normal' teaching behaviour having previously discussed the research themes, but also to allow for observed teachers to discuss the observation findings and corroborate or question the accuracy of their interpretation.

Interviews were 'semi-structured' (Bell 2010:162), and prompted by an interview schedule (see Appendix F) made up of 'open-ended' questions as advocated by Mckay (2006:52, paraphrasing Patton, 1990). Although there were clear areas of interest that I wanted to explore, I was keen not to guide or influence participants' answers too much and wanted, where possible, to take the lead from them. Interviews were recorded digitally and participants were advised at the start of the interview that the device could be stopped at any point. In addition to seeking to establish a more detailed picture of the themes explored in the questionnaire, participants were invited to discuss the notes taken in the observation as well as their opinions on the use of the CEFR for initial and summative assessment purposes. 
During the interviews notes were taken of key answers given by participants to supplement the transcribed recordings and provide a back-up should the technology fail.

\section{$\underline{\text { 3.3.2 Data analysis }}$}

In view of the sample group being relatively small, for the open-ended questions of Sections 1 and 2 of the questionnaires thematic analysis (Braun and Clarke, 2006) was applied whereby the short answers were compared and salient or unusual points extracted for reporting and key themes were identified. A similar approach was taken to the analysis of the interviews with researcher notes and transcriptions of the recorded interviews utilised. Quantitative data from Section 3 of the questionnaire was transposed into graphs using Excel, where median averages were also calculated in order to give an overview of case-sample's responses.

\section{$\underline{\text { 3.4 Ethical considerations }}$}

When designing this study care was taken for individual research instruments and the study as a whole to 'operate within an ethic of respect for any persons involved', as is outlined in the British Educational Research Association (BERA)'s 'Ethical Guidelines for Educational Research' (2011:5). The University of Sussex has their own Research Governance Code of Practice (2011) for 'low-risk' projects, which this research has been deemed to be, and this project has met all the relevant criteria.

'Voluntary Informed Consent' is prioritised in the BERA guidelines (2011) as a key tenet of respectful research. In order to ensure this, Information Sheets (see Appendix A) were 
disseminated along with the questionnaires and the accompanying Consent Form (see Appendix B). A further consent form (see Appendix D) was issued to those participants selected for the second stage of the research (observation and short interview). Prior to all of this, written consent to proceed was obtained from the Principle of the school and the Director of the department in question. Confidentiality was maintained by ascribing each participant a pseudonym ID and ensuring that digital data was stored securely.

When considering the potential 'debt incurred' (McKay 2006:24, citing Labov 1982) by those participating in research the question must be asked; can any harm be caused as a result of participation? Whilst on the surface this seems a very 'safe' piece of research, it does, in probing into teacher cognition, have the potential of challenging personal and professional beliefs in a way that may cause discomfort (see Sifakis 2007). Potential feelings of humiliation or guilt may ensue if participants were to conclude that they had hitherto not been providing learners with the most suitable model / variety of English. It was concluded that whilst it is important to be mindful of participant-teacher's beliefs and dignity in the undertaking of this research, there is no great amount of extra potential harm than what might be incurred by teachers engaging in critical reflection of their own practice.

\section{$\underline{\text { 3.5 Researcher position }}$}

In his discussion of research designed within a critical realist paradigm, Sayer reminds us of the following point: 'To make judgements about method it helps considerably if we have some idea of the nature of the relationship between ourselves and that which we seek to understand' (1992:12). I tried to take this into consideration when selecting the above instruments and approaches. 
My ideological position has been discussed in the 'Methodology' section above (3.2) and indicated in the literature review (Section 2), however, there was also an ethical element to consider: Would my colleagues feel an implicit sense of obligation to participate and share their personal (and possibly private) attitudes and approaches to practice with me? Beyond that, would my position as a colleague, working closely in small department, have an impact on how comfortable participants felt about giving their answers and how honest they were willing to be?

Of the eighteen BE teachers invited to participate in Stage 1 of the research, twelve returned completed questionnaires. Of the six who did not respond, two were involved in running other very busy projects at the time (a teacher training course and a Juniors summer school) and one was on holiday abroad with limited internet access. The three remaining teachers who did not respond had each made a point of coming to me personally, in some cases several times to say that they either would, or would really like to participate. One confided in me that she was uncertain of the terms in Section 1 and asked if there were 'right answers'. A second repeatedly apologised for not having completed it, explaining that she didn't have any spare time, yet spent fifteen minutes (the same amount of time estimated to complete the questionnaire) talking to me in a corridor, about her (highly interesting and relevant) views on ELF and its relation to BE pedagogy.

What could be the case here is that these teachers were 'face-saving', where 'face' is the 'public self-image of a person' and represents their emotional and social self (Yule 1996:60). In the case of the second teacher, who happened to be the only NNS in the department, the issue seemed to be in having her 'teacher knowledge' and attitudes recorded (in writing). I was keen to hear the views of these teachers as their lack of confidence or willingness to 
share them might indicate that they hold views that are in opposition to what they supposed I was looking for or mine might be; their reluctance could either be to save their own face or perhaps to save mine. I wanted to get as broad a range of honest views as possible but at the same time I was cautious of pressing people too heavily who may have been unwilling to participate but also unwilling to have to declare that directly.

\subsection{Data credibility and limitations}

The way in which my researcher position may have affected the data has been addressed in the section above (3.5). In order to minimise possibilities of my personal views on, or enthusiasm towards, ELF impacting on the results I refrained from informally discussing the research or the relevant topics prior to or during its undertaking.

As mentioned in Section 3.2, a MMR approach allows for triangulation and / or complementarity, which in turn help(s) to increase the validity of conclusions drawn from the data found. Whilst validity in research is important, it is somewhat difficult to measure precisely and so perhaps 'generalisability' is a more useful term.

When seeking to measure 'generalisability' the pressing question is; can the results drawn from any given research be applied outside of its context? Given the highly contextdependent nature of case-study research and the fact that 'the amount of control exerted by the researcher is minimal' in all qualitative research (McKay 2006:14), lack of generalisability is often seen as a flaw or limitation of this kind of research. In this argument I 
am aligning myself with Allwright and Bailey, cited in MacKay (2006:14), who make the case that:

'Instead of claiming that whatever has been discovered must be true of people in general, a naturalistic enquirer will claim that whatever understanding has been gained by an in-depth study of a real-life classroom may illuminate issues for other people.' (1991:51 in McKay)

Working within a Critical Realist paradigm, where our perception of reality is seen as only one facet of a greater, complex whole, whether results are generalizable or not may not be considered of such importance.

\section{Findings and discussion}

In the literature review (Section 2), several themes were identified. ELF can be seen as paradigm from which to view and teach English that stands as an alternative to the historically dominant EFL approach, built around the 'hegemonic role of the native speaker' (Sifakis 2007:360) with a continued valorisation of NS norms (see Section 2.2). For the high and growing number of international business professionals using English as a lingua franca, and learners of BE who either already participate in this world or are aspiring to, (B)ELF is a more suitable framework for teaching and learning English. Of the features of ELF talk so far identified in research and corpus analysis, I would argue that that acceptance or tolerance of variability; the co-construction; the primacy of phonological intelligibility over 'accuracy'; accommodation strategies and ICC are the most valuable and teachable aspects for BE learners. Finally, evidence suggests there is a conflict between an acknowledgement of ELF 
and ICC in recognised modern ELT training and syllabus guidelines (such as the DELTA and the CEFR, see Sections 2.2, 2.3) and the continued perpetuation of NS norms and primacy therein. Teachers, even if they are aware of the above constructs (and many appear not to be) and are in agreement with their value, seem not to reflect this in their practice. However, this research does not yet appear to have been undertaken specifically with BE teachers, for whom these constructs may be more pertinent.

In view of the above, the following RQs were derived:

\section{What are the current levels of ELF awareness in a set of BE teachers in Brighton?}

2. How pervasive are Native Speaker (NS) norms in what and how these teachers correct in class?

- Are 'ELF competencies' such as accommodation strategies, 'letting it pass', LFC phonology and ICC being taken into account?

○ Is intelligibility valued (and encouraged) above (NS-norm defined) accuracy?

○ To what extent do CEFR criteria influence their evaluation of student language competence?

In this chapter I will outline the quantitative and qualitative findings from the research undertaken and evaluate them in reference to both the RQs and the review of the relevant literature. 


\subsection{Stage 1: Questionnaire Data}

Twelve practicing BE teachers participated in the first stage of the research and returned completed questionnaires. Of these twelve, all considered themselves to be native speakers of English, with nine having taught for over two years and three for between six months and two years. In terms of qualifications, four respondents reported their highest ELT-related qualification to be the Certificate in Teaching English to Speakers of Other Languages (CELTA), seven the DELTA and one an MA. Respondents were allocated a numbered pseudonym (i.e. Teacher 1; Teacher $2 \ldots$ ) based on the order of their questionnaire return.

\subsubsection{Section 1: Teacher knowledge}

The picture drawn from this first section of the questionnaire is that the BE teachers in this sample appear to have a fairly sound awareness of the core constructs of English as a Global language, World Englishes and ELF with more variable knowledge of ICC and accommodation strategies. From the dataset some key themes emerged that are outlined below.

All twelve respondents attempted to answer the questions in the first section and all descriptions of both a) English as a Global Language and c) English as a lingua franca were sound, with some offering highly sophisticated definitions. In terms of a) English as a Global Language, respondents most frequently referred to the geographical spread of English and many mentioned its importance to the internet and international media. Encouragingly, five out of the twelve mentioned the use of English within global business in their definitions 
which indicates an awareness of the relevance of these concepts to $\mathrm{BE}$, as spelt out by one teacher:

'English has for some time now, become the Lingua Franca of the world. This is especially true of the business world and the use of Business English.' - Teacher 10

Further illustrated in the extract above is the fact that despite seeming familiarity with the terms given [a)English as a Global Language and c) English as a lingua franca], and awareness of the core concepts, there appeared to be frequent conflation between the two as exemplified in the following responses:

c) English is a lingua franca:

'Please see 'English a Global Language.'- Teacher 6

'See above (a).' - Teacher 10

a) English as a Global Language

'Not sure if this means anything different from lingua franca for me. I suppose more geographical rather than the transactional nature of a lingua franca.' - Teacher 4

One further point of note in relation to a) English as a Global Language is the way in which one respondent directly addressed the Critical Pedagogy at the heart of the global English / WE paradigms:

'... Notwithstanding perhaps inevitable literal and cultural mistranslations, English is the language of power and its status bears witness to an ugly imperialist past and modern corporatism: English makes capitalism work more smoothly'. - Teacher 6 
Whilst the Critical Pedagogy perspective (as discussed in Section 2.2) is only that -a perspective- and one that may not necessary be shared by all teachers, it is a central aspect of these terminologies and its mention indicates a thorough and nuanced understanding of the constructs. This participant, interestingly, was one of four who reported the CELTA as their highest qualification. She is also someone who grew up in an Outer Circle, post-colonial country (India), which may have been a contributing factor to her levels of awareness. I would have liked to explore her perspective further through observation and interview but she had not given her consent to be contacted for the second stage.

In terms of ELF, two key factors emerged from the majority of the descriptions: Nine respondents mentioned the fact that ELF is used between NNSs, with a further (different) nine describing its function as a contact language enabling interlocutors from different language backgrounds to communicate. In addition to this, a smaller number of respondents described some of the core features of ELF, namely its variability and the drive for cooperation, that were identified in the literature review (Section 2.1):

'That is English used as a lingua franca, but more than that, it is changing and being changed as it is used globally, and mainly between non-natives...' - Teacher 5

' I see ELF as carrying reduced cultural baggage especially as it tends to be used between non-native speakers and is open to change and interpretation' - Teacher 2

'It has the capacity to transcend difference and produce a useful if initially artificial 'sameness' that can create a space for co-operation and illumination that might otherwise be challenging to find.' - Teacher 6 
If the specific, formal terminology is somewhat unclear, the core principles appear to be very familiar to these teachers.

When it came to $b$ ) World Englishes, however, the opposite seemed to be true. On the surface there appears to be a high level of awareness of this construct with ten out of twelve specifying the 'variations of English around the world' (Teacher 1); the 'varieties of English in the world' (Teacher 8); and 'different Englishes' as defined by their differing lexis, syntax or grammar (Teacher 7). Of the six who gave examples of WEs however, only two chose examples from Outer Circle locations ('India or Nigeria'- Teacher 5; 'India, Singapore etc.'

- Teacher 11). The other four answered as follows:

'E.g. British, American, New Zealand/ Australian, South African, Indian, African, Asian, and South American' - Teacher 8

'E.g. British English, American English, Australian English and Indian English.' - Teacher 3

'Examples might be: Australian English; New Zealand English; Jamaican English etc.' - Teacher 10

'For example, differentiations between British, American, or Australian English' Teacher 12

Strikingly, not only do all of these heavily feature varieties from the NS inner circle over those from outer (or expanding) circle regions (except for Teacher 12 who gave exclusively NS examples) but in every case these have been listed first, which may indicate an implicit prioritisation. In such a small sample it is difficult to make broad assertions based on 
'patterns', but it would certainly be interesting to know whether a similar sample group based in an outer or expanding circle country might respond with a similar NS/inner circle bias. What is most interesting about these answers is that any bias for NS/ inner circle varieties seems to be unconsidered rather than explicit, particularly when taken in the context of responses such as this:

'We no longer need to consider 'just' American English or British English when teaching. There are so many variations of English.' - Teacher 10

The decision to include the terms $d$ ) Intercultural Competence (ICC) and e) Accommodation (strategies) was based on the review of the literature that found these to be crucial aspects to ELF communication (see Section 2.1). For both of these terms, less consistency of answers among participants was noted and less confidence was exhibited by individual teachers, with one respondent stating that they had 'not heard of' ICC before (Teacher 9), and four (Teachers 5, 8, 9 and 10) responding similarly about accommodation strategies. The GE teacher who undertook the pilot also expressed lack of awareness of these terms. Of the four teachers uncertain of the meaning of accommodation strategies, two had described their highest level of ELT qualification as CELTA and two as DELTA.

Key themes that emerged in response to $d$ ) Intercultural Competence (ICC), were the notions of 'respect' and 'sensitivity' towards another's culture, with five teachers including these terms in their descriptions. Further definitions included 'being able to meet someone from a different culture in the middle' (Teacher 5), and two references to 'effective' and 'efficient' communication across cultures were made (Teachers 2 and 4). A further two respondents make direct links between ICC, international business and BE instruction: 
'This could relate to common customs, what is considered to be polite/ impolite, ways of doing business (e.g. is it important to make small talk first or do they prefer to get straight down to business etc.)' - Teacher 8

'Clearly, in a business context this is key. Therefore, every 'English' course that we give, should have large elements of cross-cultural and inter-cultural training included.' - Teacher 10

Despite the uncertainty, and even when 'guessing' (Teacher 8), a consensus response was nevertheless found in relation to $e$ ) Accommodation (strategies) with eight teachers describing the modification or adaptation of language in order to match that of an interlocutor (Teachers $1,2,4,5,7,8,9,12)$. Interestingly, all of these teachers saw the onus of accommodation as falling on the speaker, with the aim of benefiting the listener by 'speaking more slowly or using less complex structures' (Teacher 12) or 'grading language' (Teacher 5). While these are valid aspects of accommodation and useful strategies, they do not acknowledge the mutual, bilateral flow of accommodation. The crucial receptive role of being prepared and willing to tolerate phonological accent variation is disregarded. This perspective also reflects the CEFR's tendency to place the responsibility of promoting understanding and preventing misunderstandings on the speaker (see Pitzl 2015). Whether this is an indication of the influence of the CEFR on teacher cognition, or of the greater way in which '[mis]understanding' is conceptualised in our culture and language it is hard to determine. The link, however, is noteworthy. 


\subsubsection{Section 2: Practical applications}

Comments on the relevance of the above constructs to classroom practice yielded highly consensual results with resounding support expressed by all teachers for the application of an ELF-centric approach to BE instruction, both in terms of how teaching is addressed and raising learner awareness. Most teachers were enthusiastic about the relevance of all terms to BE teaching, however two respondents noted that whilst WEs 'may be interesting' (Teacher 2), they 'are less significant in the workplace' (Teacher 6). These findings run contrary to fear that ELF awareness, although prevalent among researchers and academics, is not filtering through to teachers ( as discussed in Sections 2.3 and 2.4) and that 'most teachers of English are sublimely unaware of the ELF debate' (Maley 2009:196).

Further contradictory evidence was the volume of support shown for application of ICC within the BE classroom, as the following selection of responses indicate:

'Intercultural Competence is as much part of international trade as the language aspect itself.' - Teacher 3

'I think intercultural competence is in the background of much is what is done in English for professional courses. (as are awareness of ELF and E as a GL). I think the nature of multilingual small groups means that intercultural awareness is naturally developed and/ or practised. Much of the material used that has a context which assumes there will communication between people from different cultures.' - Teacher 5

'Cultural awareness is something I like to focus in class, to varying degrees. Again, this is dependent on whom they're doing business with. I often deal with different accents with my students as this is something they often request.' - Teacher 7

'I often teach about intercultural competence, as I think it's important to raise awareness about this, as lack of it could have quite an adverse effect on business relations. (Plus it's really interesting and engaging and students often have a lot to say about it!)' - Teacher 8 
In their study, Young and Sachdev (2011) found a great disparity between teacher beliefs around the value of ICC and their willingness or ability to put it into practice, with teachers seeing ICC as creating 'problems, or constraints' (Young and Sachdev 2011:82).

Nevertheless, as Pullin (2015) observed, ICC is highly relevant for BE teaching and perhaps this is why there appears to be a difference in these results from previously observed finding with GE teachers.

\subsubsection{Section 3: Evaluation of English}

In the 'Evaluation of English' stage, what is most notable is the breadth of participant reactions to each of the sample utterances. Teachers tended to respond idiosyncratically, which indicates the degree of subjectivity than underpins these evaluations. The following chart, depicting the responses of all participants to one utterance (Sentence D), has been selected to demonstrate the range of responses between participants.

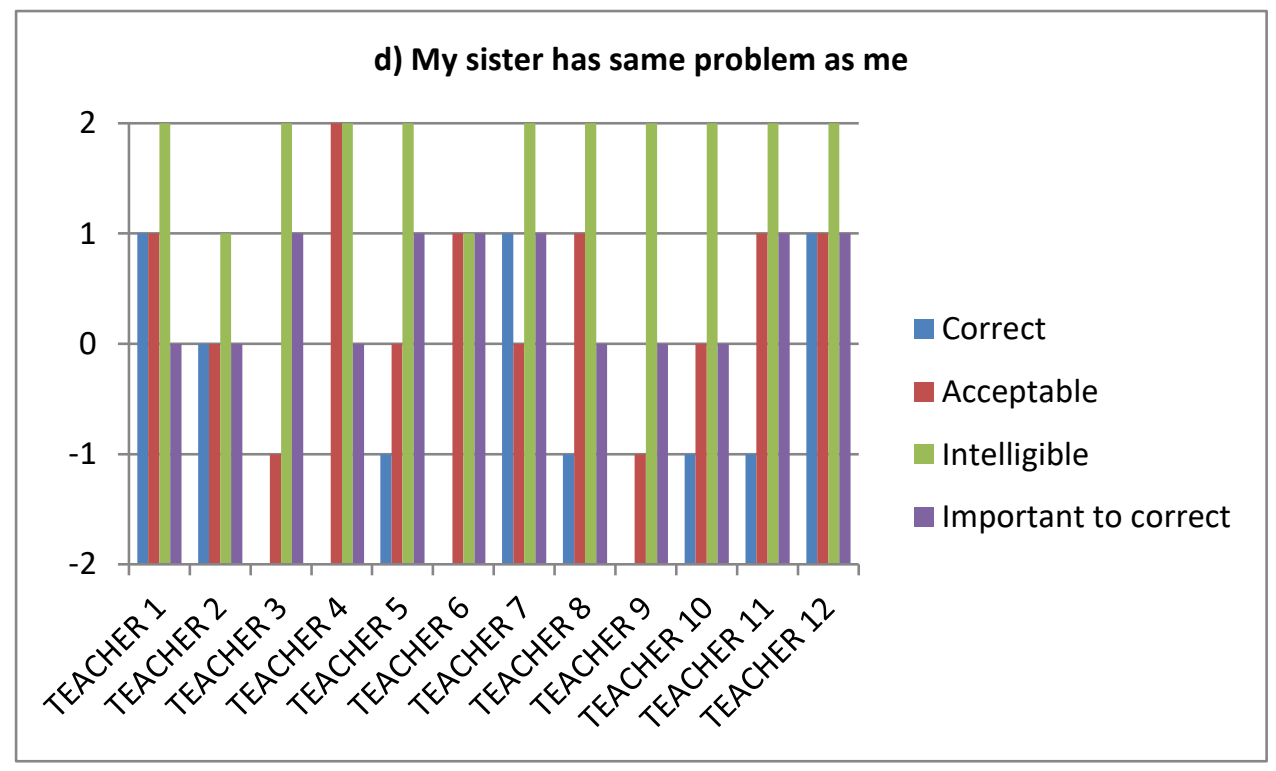


For this one utterance we can see a range of responses from 'not at all' correct (-2; Teachers $3, \mathbf{6 , 9})$ to 'somewhat' correct $(+1$; Teachers $1,7, \mathbf{1 2})$, with the same degree of variation in terms of acceptability (from 'absolutely' acceptable, +2 ; Teacher 4 to 'not very', -1 ;

Teachers 3,9 ). The one criterion that elicited a mostly consensual response was 'intelligibility'; something that will be discuss further below. If anything, what could be taken from this broad range of responses is further support that teacher cognition (i.e. teachers' beliefs and attitudes) is of great bearing on the pedagogical decision-making that informs all teaching, which in turn further highlights the importance of addressing teacher cognition both within research itself and when new, relevant information is drawn from research.

Some general themes did emerge, however, that are represented in the following diagram, showing the median values for participant responses:

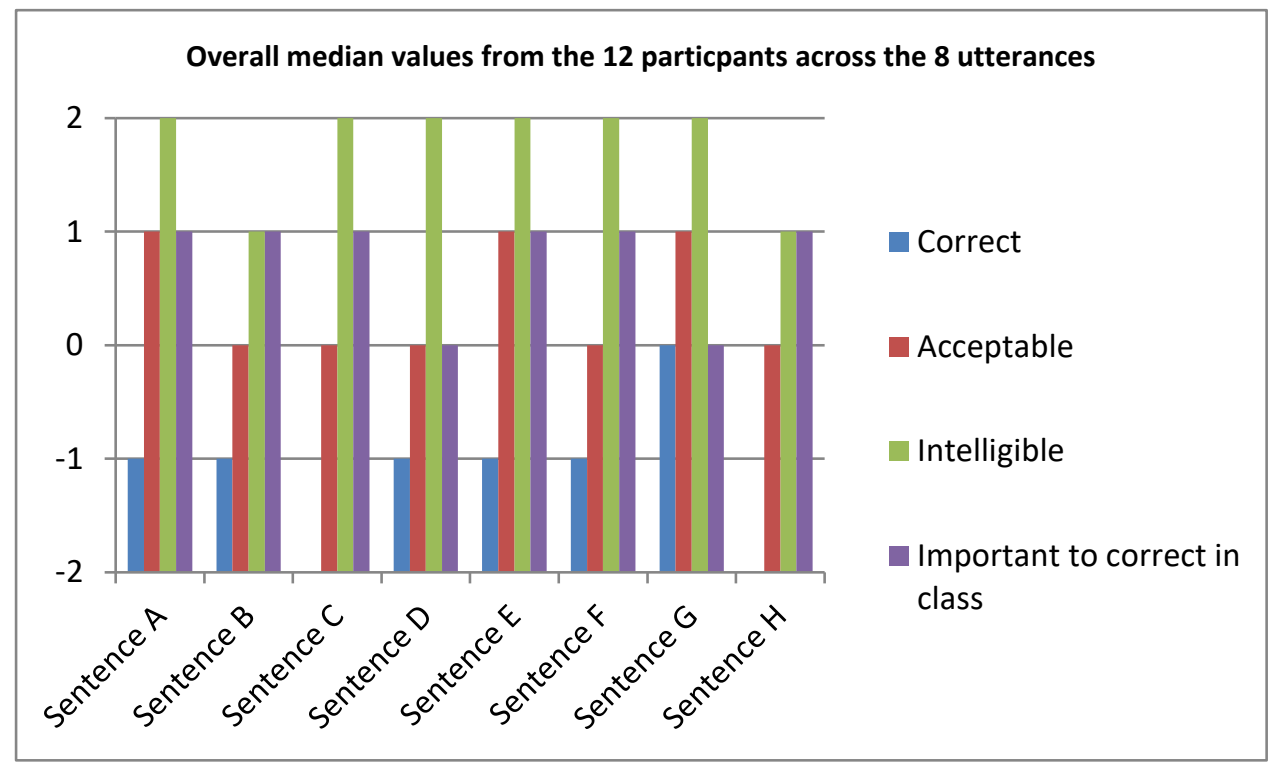

On average (the median), evaluations for all utterances were that they were 'absolutely' or 'somewhat' intelligible and either 'somewhat' acceptable or 'neutral'. This is a highly 
encouraging result, in that all teachers responded positively or neutrally to the intelligibility and acceptability of the utterances that derive from corpora of ELF talk (except for Sentence $G$ ). These responses reflect what ELF researchers (such as Seidlhofer, 2003 2005, 2011) have discovered through their empirical research; namely that the lexicogrammatical features as exemplified in the sample utterances do not seem to inhibit mutual understanding in ELF contexts. It is difficult to know whether these views held by the participants in this study are actively informed by ELF research, have been reached through personal teaching experiences and observations of learners or are a form of 'common sense'. Whatever the reason, the acknowledgement that these 'errors' are not significant for comprehension could be taken as a positive indicator of an ELF-sympathetic perspective.

Despite this, the overall evaluation in terms of 'correctness' was negative. Five utterances were rated, on average, as being 'not very' correct, with two rated as 'not at all correct' (the eighth, which was rated as 'neutral' was Sentence $G$, the American NS variety). In addition to that, six of the utterances were evaluated positively in terms of the need for classroom correction, with only two rated as neutral (Sentence $D$ and Sentence $G$ ). This highlights a disparity in evaluations that corresponds with the results of Dewey's $(2011,2012)$ research where 'teachers consistently report that they find these language forms highly intelligible, despite judging them to be very 'incorrect' when compared to established norms' (Dewey 2012: 157). Even more interestingly is how these judgements of incorrectness coordinate (or don't) with responses given in the first stage of the questionnaire:

'[WEs are] taking on the language and transmuting it so that the very notion of 'correctness' lacks validity.' - Teacher 6 
' There is no longer considered to be one standard or 'correct' form of English which should be taught or aspired to, but a multitude of Englishes, which learners of the language should be exposed to.' - Teacher 9

Analysing their evaluations of the utterances in terms of 'correctness', it can be seen that these two teachers, both of whom volunteered these views of the irrelevance of 'correct' standards, gave consistently low ratings, with Teacher 9 rating 6 utterances as 'not at all correct' $(-2)$, one as 'not very correct' $(-1)$ and only Sentence $G$ as 'somewhat correct' $(+1)$, and Teacher 6 rating every utterance as 'not at all correct' (-2). This stark inconsistency is reminiscent of Young and Sachdev's (2011) discovery that teachers' declarative knowledge and articulated opinions around ICC were often in conflict with their application of them in practice.

\subsection{Stage 2: Observations and Interviews}

The rationale for the observations and interviews and description of the two participants is given in Section 3.3.1.2, but the individual responses to the sample utterances in the questionnaire have been given here as a point of reference and as an indication of their difference in perspectives:

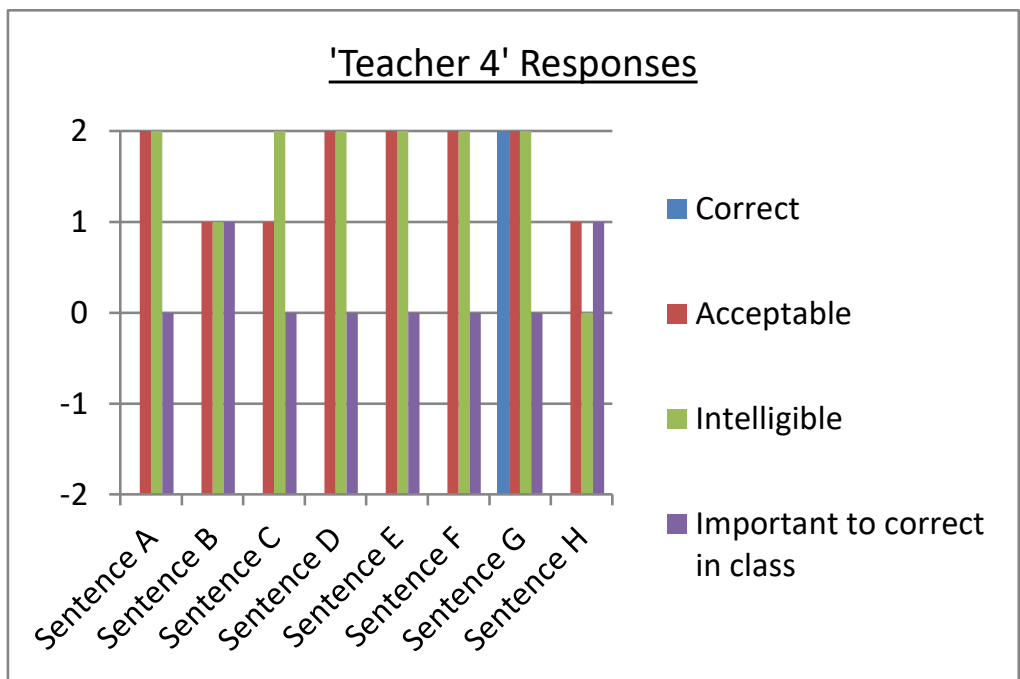




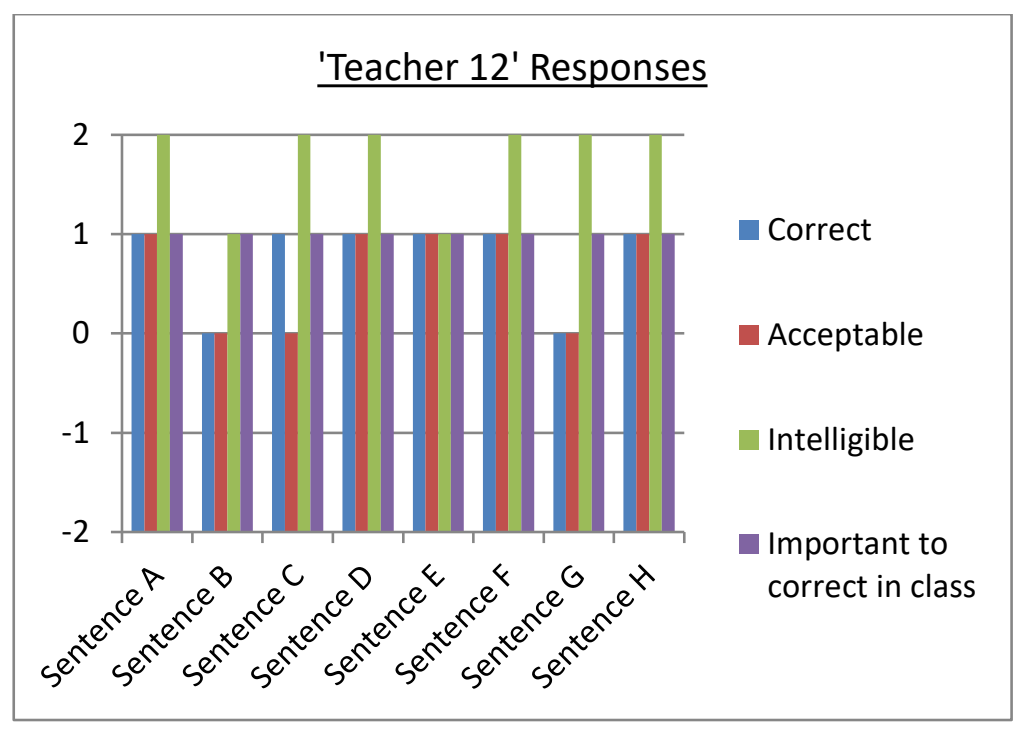

\subsubsection{Observations}

Both teachers were observed for 50 minutes. The relevant notes are summarised below:

Teacher 4 (B1 group of three- Swiss, French, Spanish):

- The teacher appeared to be taking a 'dogme' approach; drawing errors from the group conversation and expanding on them. Picking up on a learner's pragmatic misuse of the expression 'of course' near the beginning, the teacher decided to focus the lesson on 'functional language'- namely requests, offers and asking for permission.

- Phonology: The IPA chart was used to highlight long vowel sounds (in contrast to short vowel sounds) with drilling done to contrast the difference between /3:/ ('were') and /eə/ ('where'). One learner was told "be careful; you're confusing sounds and we won't understand you". One Spanish learner had difficulty distinguishing /k/ and/w/ which manifested as indistinctness between 'would' and 'could; an ambiguity that had meaning and functional implications yet was not addressed as phonological 
production issue until thirty minutes into the lesson, at which point articulation advice was given.

- The discussion of politeness, emanating from the misuse of 'of course' prompted the Swiss learner to begin to (try to) describe politeness and social rules in her country. This could have been a good opportunity to develop ICC in engaging in 'deeper exploration' 'between [the] world of familiarity and [the] world of difference' (Young and Sachdev 2011:91), however this was not pursued.

- Significant attention was drawn to the importance of considering who one's interlocutor is, in terms of being a NS or a NNS: The use of 'shall I...?' for offers was presented as potentially confusing for NNS interlocutors, and likewise the short answer to the question 'would you mind?' ['no, I wouldn't'] was underlined as being problematic and required more for dealing with NS in high-stake business conversations.

In terms of ELF awareness in the classroom, the importance of the difference between NSs and NNSs as potential interlocutors was keenly explored. The emphasis on differentiating between long and short vowels sounds accords with the proposed LFC, as does maintenance of the /3:/ sound. Intelligibility seemed to be the dominant benchmark, rather than (NS-) accuracy and this was highlighted by the direct comment about being understood. It is possible that that comment also belies possession of the belief emerging from the questionnaire data that the onus of being understood lies with the speaker. Prime opportunities to develop awareness of ICC were not taken, which could simply reflect teacher 
prioritisation of lesson time, however given the 'dogme'-style approach to the lesson it could indicate an unwillingness to engage with the topic.

\section{Teacher 12 (B2 group of three: Turkish, Italian, Spanish):}

- This teacher used his own Smartboard slides which, he explained in the subsequent interview, were an adaptation of a 'Market Leader' (BE) course-book module on Ethics. Students were asked to rate various professions and then situations in terms of ethics, working as a group to move items on the board into various categories.

- Corrections: Word stress was attended to ('mpnəひ' pplı' to 'mə'nppəlı') as was some lexical confusion ('rob someone' from 'steal someone') and interestingly a sentence similar to the first sample utterance of the questionnaire came up ('I think we need to discuss about this') and was not corrected, despite him having rated Sentence A as 'somewhat' $(+1)$ important to correct in class. In terms of further corrections, little was done within this lesson as the teacher was taking notes for detailed error correction in the final (following) lesson.

With regard to ELF awareness in the lesson then, the results were mixed. The teaching of word stress is recognised as being 'critical' within an EFL model, but seen in the LFC as unhelpful in ELF and at worst a culprit of reducing receptive flexibility (Jenkins 2002:99). In this sense, implicit NS-norms could be seen to be driving that correction. Conversely, what was most interesting about this lesson was the way in which the learners were asked to collaborate on the task and to try and reach a consensus answer. On the one hand, in view of the fact that this was a multilingual class, the activity itself provided a fantastic model of how 
communication is co-constructed within ELF talk and so could be considered as ELForientated. On the other hand, the discussion became a little heated at times and I observed that the female (Italian) learner was often not listened to or ignored by the other two (male) learners. Whist this is a difficult area to navigate, it could have been used as a springboard for addressing issues such as turn-taking/ taking-the-floor and interrupting politely. More importantly, addressing successful communicative cooperative strategies could have transformed this moment into a highly relevant learning opportunity for (B)ELF users.

Of further note was the fact that Teacher 12 used several NS idioms ('go down a rabbit hole'; 'playing devil's advocate') within the lesson, although this was also observed in Teacher 4's class ('now we get to the thorny issue'). The avoidance of 'unilateral idiomaticity' (Seidlhofer 2003:19) is widely seen within ELF research as important for promoting mutual intelligibility (e.g. Jenkins 2000; Seidlhofer 2003, 2005), and the use of it only perpetuates NS norms in manner that is NS-aggrandising. This is not to suggest that these teachers were electing to promote a NS-hegemonic stance, but the choice not to avoid these expressions, given the ELF (rather than EFL) nature of these learners that the teachers have professed awareness and support of, is interesting. This probably reflects the complexity and difficulty of being a NS-teacher teaching ELF.

There is a body of research into ELF idiomaticity and the current evidence indicates that ELF-users are highly creative with their language and often co-create new idiomatic expressions relevant to context (see Pitzl 2012; Prodromou 2007c). One, more favourable, argument for exposing learners to NS idioms could be that it raises their awareness of the generative, creative potential of the language. 


\section{$\underline{\text { 4.2.2 Interviews }}$}

From the interviews, many interesting and relevant points were raised. Two of key themes have been summarised below:

- Theme 1: The importance of a functional approach in BE teaching:

\section{Teacher 4:}

'English is English, so BE is just categorising English by a more, in a more functional way to get things done...' 'It's more about what we're trying to do with that language when we're using it.'

\section{Teacher 12:}

Researcher: 'So it sounds like having a functional focus is important in what you're selecting.'

'Yes, especially with a group like this because ... you can't really find that much common ground so the idea is it's basically communicating with each other; agreeing, disagreeing, hedging, all that kind of stuff is relevant to anything.'

'Well, I think because I'm up here in [the BE department] and we have students for a very short time, generally people want more of a functional approach to things anyway ... I think it fits in with the CEFR stuff and what you "can do".'

- Theme 2: The importance encouraging learners to consider the potential interlocutor both in terms of receptive and productive knowledge and in terms NS / NNS differences:

\section{Teacher 4:}

'I think that basically BE is more functional [than GE], so if it's more functional then the necessity to be aware of the impact on function of language, about native speaker/non-native speaker, all these kinds of categorisations becomes more important.' 


\section{On identifying 'learner needs':}

'There is a perception of needs and the true need, so first of all you allow them to present their perception of what they need. At that point you can then start talking about the ideas of native speaker, non-native speaker, receptive and productive skills because they won't have categorised language like that, most probably...'

\section{Teacher 12:}

'Given that, in terms of ELF, that the vast majority of their communication is going to be with no native speaker there, so although they might hear this stuff and it's important for comprehension, it's not always the case that they use it... if they're learning new vocabulary or new structures, it feels like oh, I've got this new stuff. I want to use it. So it's a question of making people aware that using it can cause problems and sometimes actually they might need to go back to the simpler version of what you were doing for.'

'So for example...something came up - I think it was yesterday. I think it was a piece of connected speech for example, and it just caught them out a little bit. I can't remember what - I think it was "word order" and they were like "wordor, dorder? Dord? Oh, OK, word order." And we just looked at a couple of other examples and it was a question of just making it clear: Is it important for you to do that yourself or is it more important for you to be able to understand it? So that thing of not putting loads of native sounding connected speech in their production because it's going to sound ridiculous and it's not going to help the people that they're speaking with.'

Finally, in terms of the value of the CEFR, mixed opinions were expressed. While both emphasised the importance of a functional approach to BE teaching, an approach exemplified 
in the CEFR descriptors as pointed out by Teacher 12 (above), Teacher $\mathbf{4}$ described it as a 'necessary evil' to be used only when absolutely required.

What was incredibly apparent, then, from interviewing these two teachers was the highly student-centred approach where functionality and intelligibility is prioritised over accuracy and there is an explicit focus on the differences in receptive and productive communication, particularly in the areas of phonology and pragmatics, when the imagined interlocutor is a NS or NNS. All of this seems to demonstrate a high level of practical and applied ELF awareness.

\section{Conclusion and implications for further research}

In response to the RQs, it could be summarised from the findings that there appears to be a high level of applied ELF awareness within this case-study sample of BE teachers (RQ1). NS norms still influence some teacher judgments of correctness, however attitudes towards classroom correction were observed and reported to be driven more by intelligibility than NS norms (RQs 2). In terms of 'ELF Competences' (RQ2), aspects of the LFC appeared to be put into practice, although this seemed to be based on contextually acquired teacher-knowledge of their BE learners' needs rather than direct application of the LFC. ICC was reported as being highly relevant to the participants' BE teaching (although this was not directly observed by the researcher) and in terms of the CEFR's influence, a functional approach to ELT and attitudes to [mis]understanding that put the onus on the speaker could be observed 
as correlating with CEFR, although it is not possible to know whether there is any influential link at this stage.

Overall the findings from the research appear to contradict what might have been expected based on the review of current literature documenting research into teacher-attitudes and awareness of ELF and ICC; and their willingness to apply this knowledge to their practice. Given the inherent ELF needs of BE learners it could be possible to infer that the teachers in this case-study sample, in adopting a student-centred approach based on detailed needs analyses, have been better sensitised to (B)ELF and the needs of its learner-users and have developed their own 'situated methodologies' (Ur 2013:470).

\section{$\underline{5.1 \text { Limitations }}$}

Feedback from both participants in the interviews regarding the 'Evaluation of English' section of the questionnaire was that the scale did not allow them to express their opinions fully or particularly accurately. A contextual dimension was observed as being absent in the wording and an alternative question of 'would you correct this, and why?' was suggested (by Teacher 12). It is true that this section of the questionnaire asks teachers to evaluate sample utterances that are completely decontextualised; a situation not especially reflective of reallife and this should be considered when interpreting the results. A further limitation of this section of the questionnaire is that it is presenting what were originally spoken utterances in a written form; better, perhaps, would have been to play teachers direct recordings with the added dimension of phonology. 


\subsection{Implications for further research}

This study supports the call that there is a need to research teacher cognition in relation to ELF more widely. In this case, the findings appear to contradict those of previous research and whilst it is tempting to infer that there may be differences in the levels of GE and BE teachers' awareness of ELF (and ICC) and their willingness to apply this to teaching practice, the small size of this sample means that a much wider-reaching survey of BE teachers would be required before any tentative conclusions could be drawn. This study did not seek to discover the extent to which ELF awareness was derived from engagement with research and this may be a further interest to pursue.

Findings from this research indicated that despite an ELF-sympathetic attitude, teachers still seemed to be influenced, to a greater or lesser extent by NS-norms and to hold attitudes that correlated with those expressed in the CEFR. It would be interesting to compare these results with a comparable sample group of either NNS BE teachers or BE based in a NNS territory. A further potential area of research could be to investigate the extent to which the CEFR directly or indirectly informed BE and GE teacher cognition.

Word Count 16,313

\section{$\underline{\text { 6. References and bibliography }}$}

Archibald, A., Cogo, A. and Jenkins, J. (2011) Latest trends in ELF research. Newcastle upon Tyne: Cambridge Scholars Publishing

Baker, W. (2015) Culture and complexity through English as a lingua franca: rethinking competences and pedagogy in ELT. Journal of English as a Lingua Franca, 4(1):9-30. 
British Educational Research Association (2011) Ethical guidelines for educational research ( $2^{\text {nd }}$ Revision). Available online at: https://www.bera.ac.uk/researchersresources/publications/ethical-guidelines-for-educational-research-2011. Accessed 10/07/2016.

Bell, J. (2010) Doing your research project: A Guide for First-time Researchers in Education, Health and Social Science ( $5^{\text {th }}$ edn.). Maidenhead: OUP

Bourdieu, P. (1986). The forms of capital. In Szeman, I. \& Kaposy, T. (2011).Cultural theory: An anthology. Chapter 8:81-84. (s.1.) Wiley-Blackwell.

Borg, S. (2003) Teacher cognition in language teaching: A review of research on what language teachers think, know, believe, and do. Language teaching, 36(02):81-109.

Braun, V. and Clarke, V. (2006) Using thematic analysis in psychology.Qualitative research in psychology, 3(2):77-101.

Byram, M.S. \&Feng, A. (2005) Teaching and researching intercultural competence. In: Hinkel, E. (ed.) Handbook of research in second language teaching and learning. Mahwah, NJ: Lawrence Earlbaum: 911-930

Canagarajah, S. Critical Pedagogy in L2 Learning and Teaching (2005). In: Hinkel, E. (ed.) Handbook of research in second language teaching and learning. Mahwah, NJ: Lawrence Earlbaum: 911-930

Canale, M. and Swain, M. (1980) Theoretical bases of communicative approaches to second language teaching and testing. Applied linguistics,1(1):1-47.

Cogo, A. and Dewey, M. (2006) Efficiency in ELF communication: From pragmatic motives to lexico-grammatical innovation. Nordic Journal of English Studies, 5(2):59-93.

Council of Europe (CoE) (2001) Common European framework of reference for languages: Learning, teaching, assessment. Cambridge: CUP

Crystal, D. (2008) Two thousand million? English Today, 93:3

Dauer, R.M. (2005) The Lingua Franca Core: A new model for pronunciation instruction? Tesol Quarterly, 39(3): 543-550.

Dewey, M. (2011) Accommodative ELF talk and teacher knowledge. In, Archibald, Cogo \&Jenkins (eds.), Latest Trends in ELF Research. Newcastle: Cambridge Scholars Publishing.

Dewey, M. (2012) Towards a post-normative approach: Learning the pedagogy of ELF. Journal of English as a Lingua Franca 1(1):141-170

Ellis, R. (2009) Second language acquisition, teacher education and language pedagogy. Language Teaching 43/2; 182-201. 
Erhenreich, S. (2011) The Dynamics of English as a lingua franca in International Business. In: Archibald, A., Cogo, A. and Jenkins, J (eds.) Latest Trends in ELF Research. Newcastle upon Tyne: Cambridge Scholars Publishing:11-34

Firth, A. (2009) The lingua franca factor. Intercultural pragmatics, 6(2):147-170.

Graddol, D. (2006) English Next (Vol. 62). London: British Council.

Hall, C.J. (2014) Moving beyond accuracy: from tests of English to tests of 'Englishing'. ELT Journal, 68(4):376-385.

House, J. (2009) Introduction: The pragmatics of English as a lingua franca. Intercultural Pragmatics, 6(2):141-145.

Hynninen, N. (2014) The Common European Framework of Reference from the perspective of English as a lingua franca: What we can learn from a focus on language regulation. Journal of English as a Lingua Franca, 3(2):293-316.

Jenkins, J. (2000) The phonology of English as an international language. Oxford: OUP Jenkins, J. (2002) A sociolinguistically based, empirically researched pronunciation syllabus for English as an international language. Applied Linguistics, 23(1):83-103.

Jenkins, J. (2006) Current perspectives on teaching world Englishes and English as a lingua franca. Tesol Quarterly, 40(1):157-181.

Jenkins, J. (2007) English as a Lingua Franca: Attitude and Identity. Oxford: OUP

Jenkins, J., Cogo, A. and Dewey, M. (2011) Review of developments in research into English as a lingua franca. Language Teaching, 44(03):281-315.

Kachru, B. (1992) The other tongue: English across cultures. Urbana:University of Illinois Press.

Kankaanranta, A. and Planken, B. (2010) BELF competence as business knowledge of internationally operating business professionals. Journal of Business Communication, 47(4):380-407.

Kuo, I.C.V. (2006) Addressing the issue of teaching English as a lingua franca. ELT journal, 60(3):213-221

Levis, J.M. (2005) Changing contexts and shifting paradigms in pronunciation teaching. TESOL Quarterly 39 (3):369-377

Maley, A. (2009) ELF: A teacher's perspective. Language and Intercultural Communication, 9(3):187-200.

McKay, S.L. (2002) Teaching English As An International Language: Rethinking Goals and Perspectives. New York: OUP 
McKay, S. (2006) Researching Second Language Classrooms. Mahwah, NJ: Lawrence Earlbaum.

McNamara, T. (2012) English as a lingua franca: The challenge for language testing. Journal of English as a Lingua Franca 1(1):199-202

Mehdi Riazi, A. and Candlin, C. (2014) Mixed-methods research in language teaching and learning: Opportunities, issues and challenges. Language Teaching 47(2):135-173.

Murray, N. (2012) English as a lingua franca and the development of pragmatic competence. ELT journal, 66(3):318-326.

Neeley, T. (2012) Global Business Speaks English. Harvard Business Review. Available at: https://hbr.org/2012/05/global-business-speaks-english. Accessed 13/08/2016

Newman, B. (1996) Global chatter: The reality of 'business English'. English Today, 12(02): $16-20$.

Pennycook, A. (1994) The Cultural Politics of English as an International Language. London: Longman.

Pickering, L. (2009) Intonation as a pragmatic resource in ELF interaction. Intercultural Pragmatics, 6(2):235-255.

Pitzl, M.L. (2012) Creativity meets convention: Idiom variation and remetaphorization in ELF. Journal of English as a Lingua Franca 1(1):27-55.

Pitzl, M.L. (2015) Understanding and misunderstanding in the Common European Framework of Reference: what we can learn from research on BELF and Intercultural Communication. Journal of English as a Lingua Franca, 4(1):91-124.

Prodromou, L. (2007a) A Reader Responds to J. Jenkins's "Current Perspectives on Teaching World Englishes and English as a Lingua Franca”. Tesol Quarterly, 41(2):409-413

Prodromou, L. (2007b) Is ELF a variety of English?. English Today, 23(2):47-53.

Prodromou, L. (2007c) Bumping into creative idiomaticity. English Today, 23(1):14-25.

Pullin, P. (2013) Achieving "comity": The role of linguistic stance in business English as a lingua franca (BELF) meetings. Journal of English as a Lingua Franca, 2(1):1-23.

Pullin, P. (2015) Culture, curriculum design, syllabus and course development in the light of BELF. Journal of English as a Lingua Franca,4(1):31-53.

Sayer, A. (1992) Method in Social Science: 2nd Edition. London: Routledge.

Seidlhofer, B. (2003) A concept of International English and related issues: from 'real English' to 'realistic English' ? Council of Europe. Available online at http://www.coe.int/T/DG4/Linguistic/Source/SeidlhoferEN.pdf (Accessed 13/05/2016) 
Seidlhofer, B. (2005) English as a lingua franca. ELT journal, 59(4):339.

Seidlhofer, B. (2009) Common ground and different realities: World Englishes and English as a lingua franca. World Englishes, 28(2):236-245.

Seidlhofer, B. (2011) Understanding English as a Lingua Franca. Oxford: OUP.

Sifakis, N. (2007) The education of teachers of English as a lingua franca: a transformative perspective. International Journal of Applied Linguistics, 17(3):355-375.

The Economist (Feb 15 ${ }^{\text {th }}$ 2014) The English Empire. Available at: http://www.economist.com/news/business/21596538-growing-number-firms-worldwide-areadopting-english-their-official-language-english. Accessed 13/08/2016

Timmis, I. (2002) Native-speaker norms and International English: a classroom view. ELT journal, 56(3):240-249.

Timmis, I. (2012) Spoken language research and ELT: where are we now? ELT journal, 66(4):514-522.

University of Sussex (2011) Research Governance Code of Practice. Available online at: http://www.sussex.ac.uk/staff/research/governance. (Accessed on 10/07/2016)

Ur, P. (2013) Language-teaching method revisited. ELT journal, 67(4):468-474.

van Lier, L. (2005) Case Study. In: Hinkel, E. (ed.) Handbook of research in second language teaching and learning. Mahwah, NJ: Lawrence Earlbaum:195-208

Wells, J.C. (2005) Goals in teaching English pronunciation. In Dziubalska-Kolaczyk, K. and Przedlacka, J. (eds.) English pronunciation models: A changing scene:101-110.

Widdowson, H.G. (1997) EIL, ESL, EFL: Global issues and local interests. World Englishes, 16(1):135-146.

Widdowson, H.G. (2013) ELF and EFL: what's the difference Comments on Michael Swan. Journal of English as a Lingua Franca, 2(1):187-193

Young, T.J. \& Sachdev, I. (2011) Intercultural communicative competence: Exploring English language teachers' beliefs and practices. Language awareness, 20(2):81-98.

Yule, G. (1996) Pragmatics. Oxford: OUP

Yule, G. (2006). The Study of Language (3rd edn.). Cambridge: CUP 


\section{Appendix A) Participant information sheet}

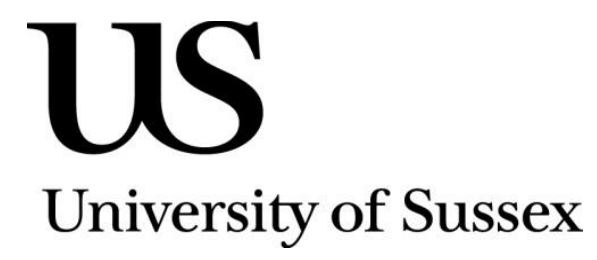

\section{MA Research into Business English Teachers' Attitudes and Practices: Participant Information}

As a teacher who has taught Business English, (or 'English for Professionals'), you are being invited to take part in a research study forming part of my MA in ELT. Before you decide whether or not to take part, please take time to read the following information carefully:

The aim of the research is to get an understanding of the attitudes, beliefs and practices of in-service Business English teachers in relation to a particular topic (undisclosed so as not to steer your answers).

You are being asked to complete a short questionnaire, which, if you chose to participate, I request that you please return this to me by Monday 18th July.

Two participants will be invited to be involved in a second stage involving one observed lesson and a short follow-up interview. It is not necessary to commit to both stages. If you are willing to be contacted regarding the observation and follow-up interview please indicate this in the relevant section at the end of the questionnaire.

Confidentiality will be strictly observed throughout the data collection and reporting. Your names will not be used in the reporting of the data and no information that you disclose will lead to your identification, to that of any other individual or of your place of work.

You may opt out of this research at any stage.

Results of this research will be included in my MA ELT dissertation, with the possibility of future publication.

This study has been approved by the School of English at the University of Sussex.

If you have any further questions regarding this study or your participation within it, please contact Gemma Williams-djezmalouiz@gmail.com

Thank you for taking the time to read this information. If you chose to support this research by participating please return the questionnaire along with the attached consent form to the email above by 18 th July 2016. 


\section{$\underline{\text { Appendix B) Stage } 1 \text { (Questionnaire) consent form }}$}

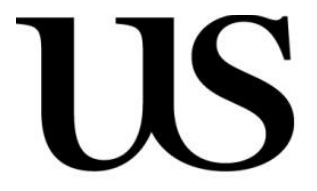

\section{University of Sussex}

\section{CONSENT FORM FOR PROJECT PARTICIPANTS}

\section{PROJECT TITLE: MA Research into Business English Teachers' Attitudes and Practices.}

I agree to take part in the above University of Sussex research project. I have read and understood the Information Sheet, which I may keep for records. I understand that agreeing to take part means that I am willing to:

- Submit my questionnaire answers by email to the researcher.

I understand that any information I provide is confidential, and that no information that I disclose will lead to the identification of any individual in the reports on the project, either by the researcher or by any other party.

I understand that my participation is voluntary, that I can choose not to participate in part or all of the project, and that I can withdraw at any stage of the project without being penalised or disadvantaged in any way.

I consent to the processing of my personal information for the purposes of this research study. I understand that such information will be treated as strictly confidential and handled in accordance with the Data Protection Act 1998.

Name: $\mathrm{x}$

Date: $\mathrm{x}$

(If completing digitally, your name entered in the above field will count as your signature) 


\section{Appendix C) Questionnaire}

\section{Business English Teachers' Attitudes and Practices}

\section{Section 1: Teacher Knowledge}

Please describe what you understand by the following terms:

a) 'English as a Global language'

b) 'World Englishes'

c) 'English as a lingua franca' (ELF)

d) 'Intercultural Competence' (ICC)

e) 'Accommodation (strategies)' 


\section{Section 2: Practical applications}

In what ways, if any, do you consider these concepts (English as a Global language, World Englishes, English as a lingua franca and Intercultural Competence, Accommodation Strategies) relevant in your Business English language teaching? Why / Why not?

Please write some brief comments describing your opinions:

\section{Section 3: Evaluation of English}

In the following final section, please rate the following utterances in relation to the following dimensions:

a) level of correctness, b) acceptability, c) intelligibility, and d) importance (in terms of needing to be 'corrected' in the classroom).

For each utterance, please put an $X$ or tick in the relevant box, using the following scale:

$\begin{array}{rrrrc}\text { Not at all } & \text { Not very } & \text { Neutral } & \text { Somewhat } & \text { Absolutely } \\ -2 & -1 & 0 & +1 & +2\end{array}$




\begin{tabular}{|ccccc|}
\hline Not at all & Not very & Neutral & Somewhat & Absolutely \\
-2 & -1 & 0 & +1 & +2 \\
\hline
\end{tabular}

a) We need to discuss about the problem.

\begin{tabular}{|l|l|l|l|l|l|}
\hline & $\mathbf{- 2}$ & $\mathbf{- 1}$ & $\mathbf{0}$ & $\mathbf{+ 1}$ & $\mathbf{+ 2}$ \\
\hline correct & & & & & \\
\hline acceptable & & & & & \\
\hline intelligible & & & & & \\
\hline important to correct in class & & & & & \\
\hline
\end{tabular}

b) Last summer I was happy because I finally took my driving license.

\begin{tabular}{|l|l|l|l|l|l|}
\hline & $\mathbf{- 2}$ & $\mathbf{- 1}$ & $\mathbf{0}$ & $\mathbf{+ 1}$ & $\mathbf{+ 2}$ \\
\hline correct & & & & & \\
\hline acceptable & & & & & \\
\hline intelligible & & & & & \\
\hline important to correct in class & & & & & \\
\hline
\end{tabular}

c) I enjoy listening classical music.

\begin{tabular}{|l|l|l|l|l|l|}
\hline & $\mathbf{- 2}$ & $\mathbf{- 1}$ & $\mathbf{0}$ & $\mathbf{+ 1}$ & $\mathbf{+ 2}$ \\
\hline correct & & & & & \\
\hline acceptable & & & & & \\
\hline intelligible & & & & & \\
\hline important to correct in class & & & & & \\
\hline
\end{tabular}


d) My sister has same problem as me.

\begin{tabular}{|l|l|l|l|l|l|}
\hline & $\mathbf{- 2}$ & $\mathbf{- 1}$ & $\mathbf{0}$ & $\mathbf{+ 1}$ & $\mathbf{+ 2}$ \\
\hline correct & & & & & \\
\hline acceptable & & & & & \\
\hline intelligible & & & & & \\
\hline important to correct in class & & & & & \\
\hline
\end{tabular}

e) Pollution is a major issue and a big problem for the nature.

\begin{tabular}{|l|l|l|l|l|l|}
\hline & $\mathbf{- 2}$ & $\mathbf{- 1}$ & $\mathbf{0}$ & $\mathbf{+ 1}$ & $\mathbf{+ 2}$ \\
\hline correct & & & & & \\
\hline acceptable & & & & & \\
\hline intelligible & & & & & \\
\hline important to correct in class & & & & & \\
\hline
\end{tabular}

f) In my country everybody have to do military service.

\begin{tabular}{|l|l|l|l|l|l|}
\hline & $\mathbf{- 2}$ & $\mathbf{- 1}$ & $\mathbf{0}$ & $\mathbf{+ 1}$ & $\mathbf{+ 2}$ \\
\hline correct & & & & & \\
\hline acceptable & & & & & \\
\hline intelligible & & & & & \\
\hline important to correct in class & & & & & \\
\hline
\end{tabular}

g) I didn't finish reading the book yet.

\begin{tabular}{|l|l|l|l|l|l|}
\hline & $-\mathbf{2}$ & $\mathbf{- 1}$ & $\mathbf{0}$ & $\mathbf{+ 1}$ & $\mathbf{+ 2}$ \\
\hline correct & & & & & \\
\hline acceptable & & & & & \\
\hline intelligible & & & & & \\
\hline important to correct in class & & & & & \\
\hline
\end{tabular}


h) It's difficult to know how to draw the limits.

\begin{tabular}{|l|l|l|l|l|l|}
\hline & $\mathbf{- 2}$ & $\mathbf{- 1}$ & $\mathbf{0}$ & $\mathbf{+ 1}$ & $\mathbf{+ 2}$ \\
\hline correct & & & & & \\
\hline acceptable & & & & & \\
\hline intelligible & & & & & \\
\hline important to correct in class & & & & & \\
\hline
\end{tabular}

Please use the following box to write any additional comment you may have, should you have any, regarding your answers above: 
Length of time teaching Business English (Please enter an $X$ or tick):

$<6$ months

6 months -2 years

2 years +

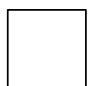

Do you consider yourself to be a Native Speaker of English? (Please enter an X or tick):

Yes

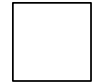

No

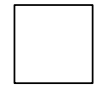

What is your highest level of TEFL training or study (For example CELTA, DELTA etc.)?

\section{*Thank you for giving your time to complete this questionnaire*}

If you would be willing to be observed (one lesson) and to undertake a short follow-up interview (<30 mins) in within the next few weeks, please give your email address below:

(Your email address will only be used to contact you to discuss arranging an observation time). 


\section{Appendix D) Stage 2 (Observation \& Interview) consent form}

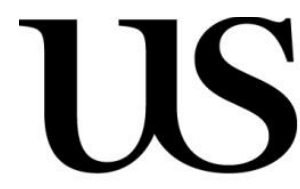

\section{University of Sussex}

\section{CONSENT FORM FOR PROJECT PARTICIPANTS}

\section{PROJECT TITLE: MA Research into Business English Teachers' Attitudes and Practices. Stage 2) Observation and Interviews}

I agree to take part in the second stage of the above University of Sussex research project which is bound by the same terms as described in the original Information Sheet. I understand that agreeing to take part means that I am willing to:

- Be interviewed by the researcher.

- Be observed in my Business English teaching by the researcher.

- Consider allowing the researcher to digitally record the above.

I understand that my participation is voluntary, that I can choose not to participate in part or all of the project, and that I can withdraw at any stage of the project without being penalised or disadvantaged in any way. I may ask for my observation / interview not to be recorded or I may stop the recording at any point.

I understand that any information I provide is confidential, and that no information that I disclose will lead to the identification of any individual in the reports on the project.

I consent to the processing of my personal information for the purposes of this research study. I understand that such information will be treated as strictly confidential and handled in accordance with the Data Protection Act 1998.

Name: $\mathrm{x}$

Date: $\mathrm{x}$

(If completing digitally, your name entered in the above field will count as your signature) 


\section{$\underline{\text { Appendix E) Observation check-list }}$}




\section{Appendix F) Interview schedule}

